Article

\title{
Land Cover Change Image Analysis for Assateague Island National Seashore Following Hurricane Sandy
}

\author{
Heather Grybas * and Russell G. Congalton \\ Department of Natural Resources and the Environment, University of New Hampshire, 114 James \\ Hall, 56 College Road, Durham, NH 03824, USA; E-Mail: russ.congalton@unh.edu \\ * Author to whom correspondence should be addressed; E-Mail: hmg10@wildcats.unh.edu; \\ Tel.: +1-603-862-4644.
}

Academic Editors: Gonzalo Pajares Martinsanz and Francisco Rovira-Más

Received: 1 September 2015 / Accepted: 30 September 2015 / Published: 5 October 2015

\begin{abstract}
The assessment of storm damages is critically important if resource managers are to understand the impacts of weather pattern changes and sea level rise on their lands and develop management strategies to mitigate its effects. This study was performed to detect land cover change on Assateague Island as a result of Hurricane Sandy. Several single-date classifications were performed on the pre and post hurricane imagery utilized using both a pixel-based and object-based approach with the Random Forest classifier. Univariate image differencing and a post classification comparison were used to conduct the change detection. This study found that the addition of the coastal blue band to the Landsat 8 sensor did not improve classification accuracy and there was also no statistically significant improvement in classification accuracy using Landsat 8 compared to Landsat 5. Furthermore, there was no significant difference found between object-based and pixel-based classification. Change totals were estimated on Assateague Island following Hurricane Sandy and were found to be minimal, occurring predominately in the most active sections of the island in terms of land cover change, however, the post classification detected significantly more change, mainly due to classification errors in the single-date maps used.
\end{abstract}

Keywords: Assateague Island; Hurricane Sandy; change detection; Landsat 8; object-based classification 


\section{Introduction}

Hurricanes and other large coastal storms have significant impacts on human and vegetation communities but they are also important agents of ecological succession in coastal ecosystems [1,2]. There are direct impacts to coastal vegetation such as damages caused by wind and storm surge $[3,4]$ or from increased soil salinity following a storm surge $[2,5,6]$. These impacts can alter vegetation patterns within coastal habitats causing minor to irreversible changes to the landscape which in turn affects the wildlife communities that utilize these unique and rare coastal habitats. It is expected that there will be an increase in the frequency and intensity of hurricanes and other extreme storm events due to the effects of changing global weather patterns $[7,8]$. Sea level is also expected to continue rising due to glacial melting resulting in larger storm surges, greater flood damage and shoreline erosion [7,9,10]. These factors make the accurate assessment of hurricane damages to coastal ecosystems critically important if resource managers are to understand how these changes may impact their lands so improved management strategies can be developed $[2,6,9]$.

These kinds of assessments need to be rapid and be easily repeatable so that potential problem areas can be identified and mitigation strategies developed in a timely manner [11]. Remote sensing provides a means by which hurricane impacts can be assessed over large areas quickly, accurately, and repeatedly [2,5,6]. Because of its repetitive data collection, synoptic view, and digital format, remotely sensed data has become an important resource for monitoring land cover change resulting from human and natural processes [12] and has been extensively used in a number of other studies assessing hurricane damage to coastal ecosystems [2-6,9,13-15]

There is a variety of satellite remotely sensed imagery that can be utilized for studies involving land cover classification and change detection. For over 40 years the Landsat program has been providing moderate spatial resolution imagery that has proven to be invaluable for a large number of studies in a wide variety of different disciplines [16,17]. While there are a number of sources for higher spatial resolution imagery (e.g., Ikonos, Quickbird, Worldview), Landsat imagery has higher spectral resolution (i.e., senses in more wavelengths) than most high spatial resolution data, covers a larger extent, and since 2008 is freely available, making repeat land cover analysis possible. The latest generation of Landsat satellites, Landsat 8, was launched 11 February 2013 and brings with it several improvements. Previous Landsat sensors had a radiometric resolution of 8 bits or 256 possible values, but the new Operational Land Imager (OLI) sensor onboard Landsat 8 collects 12 bit data which increases the number of potential values to 4096. This increase in radiometric resolution enhances the sensor's ability to detect small changes in the amount of energy reflected from objects on the Earth surface and can lead to an improved ability to distinguish between objects with similar spectral patterns [18]. The OLI also has three new bands, a blue band for coastal and aerosol studies, a shortwave infrared band for cloud detection, and finally a quality assessment band used to indicate possible bad pixels [19]. Furthermore, the spectral range of most of the original bands, especially the NIR and SWIR bands, were narrowed to reduce the effects of water absorption [20,21]. Because of these improvements, Landsat 8 is expected to produce superior analysis results compared to previous Landsat sensors [22-24]. Given the recent availability of this imagery, little work has been formally published testing these enhancements; nevertheless, a few have shown improved results $[20,25]$. 
Land cover classification has typically been accomplished using a pixel-based approach, where by each pixel is independently classified using only the spectral reflectance values for that pixel [26-28]. Recently, object-based image analysis (OBIA) has been utilized for image classification and change detection and has resulted in a significant improvement in accuracy especially for high spatial resolution imagery [29-32]. Unlike the traditional pixel-based approach, OBIA starts by first segmenting an image into spatially and/or spectrally homogenous, non-overlapping, groupings of pixels known as image objects. The objects are then assigned a land cover class much like pixels by a classification algorithm. Objects have an advantage over pixels in that they contain spatial and spectral information that single pixels do not such as mean band values, mean ratios, size, shape, and topological relationships that can all be utilized during the classification process $[33,34]$.

OBIA is frequently used to extract information from high resolution imagery; however, it is not limited to such imagery. While it can be used with moderate resolution data like Landsat, it has been unclear whether there is an improvement in accuracy when doing so. Studies that have made comparisons between pixel-based (PBC) and object-based (OBC) classification with moderate resolution data have reached differing conclusions; some finding OBC outperformed PBC [35-37] while other have found the opposite to be true [38]. Several studies found no significant difference between methods $[39,40]$.

Detecting and measuring change is important when studying natural resources. It can be accomplished using two broad approaches. The first approach involves the comparison of two individually classified maps. Post classification comparison (PCC) is a very popular method within this approach and is perhaps the most commonly used methodology for change detection in general [41]. It involves overlaying two land cover maps from different dates and identifying the differences between the classifications. The second approach involves analyzing multi-temporal data concurrently. While the second approach is comprised of numerous methodologies, univariate image differencing (UID) is often cited as the preferred method [42]. Furthermore, it is also the recommended change detection method of the National Oceanic and Atmospheric Administration (NOAA) Coastal Change Analysis Program (C-CAP) which, as part of the program, developed a comprehensive protocol for the implementation of land cover classification and change detection for coastal regions in the US from remotely sensed data [43].

The main objective of this study was to quantify and qualify the type and amount of land cover change that occurred on Assateague Island as a result of Hurricane Sandy. In addition to detecting land cover change, several additional objectives were established including, evaluating the contribution of the new Landsat 8 bands to classification accuracy, comparing the performance of Landsat 8 for land cover classification with Landsat 5, comparing $\mathrm{OBC}$ and $\mathrm{PBC}$ using moderate resolution data, and comparing the results of PCC to UID for change detection. Our results show that given the level of classification detail (i.e., map classes) in this study, the new Landsat 8 coastal blue band did not improve classification accuracy. Also, there was no statistically significant difference in classification accuracy between using Landsat 8 compared to Landsat 5, again at the level of land cover detail utilized. Furthermore, there was no significant difference between $\mathrm{OBC}$ and PBC. Finally, while land cover change totals were found to be minimal on Assateague Island, issues of thematic error associated with the PCC methodology results in significantly higher amounts of change identified compared to the UID. 


\section{Methods}

\subsection{Study Area}

Assateague Island is an undeveloped barrier island and part of the Delmarva (Delaware-Maryland-Virginia) Peninsula on the Mid-Atlantic Coast (Figure 1). Assateague is managed by three government agencies. The National Park Service (NPS) manages most of the land within the Maryland portion of the island as well as some within Virginia. The U.S Fish and Wildlife Service (USFWS) manage the lands within the rest of Virginia known as the Chincoteague National Wildlife Refuge. The third agency is the Maryland Park Service (MPS) who manages a small, $3 \mathrm{~km}$ long portion of the island within Maryland as a state park. The island is mostly undeveloped with the exception of a few roads and parking lots, as well as campgrounds [44]. Coastal storms are responsible for creating and maintaining a number unique habitat types that support a variety of important species such as the threatened piping plover (Charadrius melodus) as well as numerous migratory birds, deer, and the famous wild horses [45].

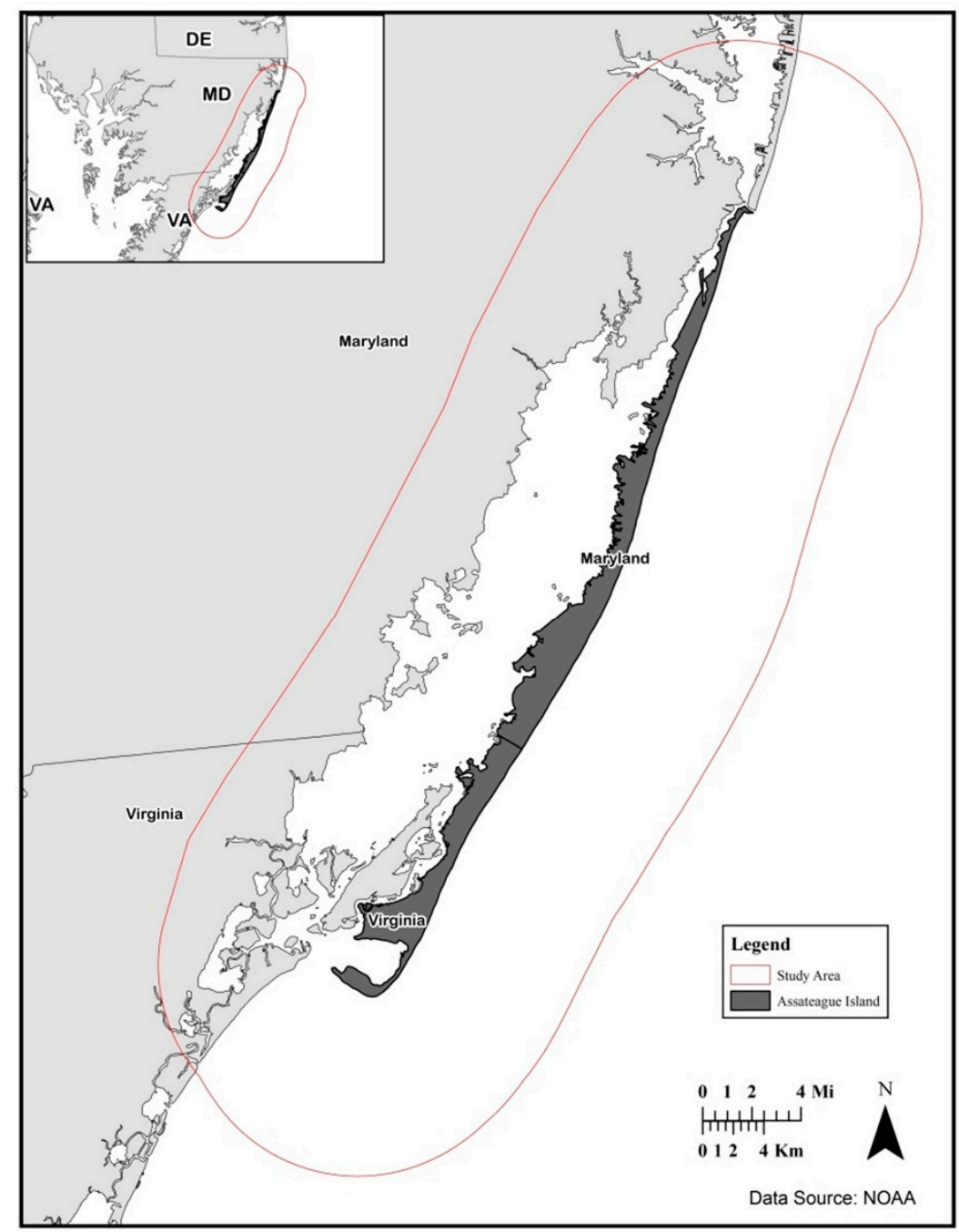

Figure 1. States shown include Delaware (DE), Maryland (MD), and Virginia (VA), located in the United States. The study area boundary shown in red includes both Assateague Island (dark grey) and a portion of the surrounding mainland (light gray). 
The island can be broken into three sections. The northern $10 \mathrm{~km}$ of the island, also known as the North End, is a dynamic, storm structured environment that is much lower and narrower relative to the rest of the island. The North End has seen significant changes as a result of anthropogenic modifications. A jetty built in 1934 to hold open the Ocean City inlet has disrupted longshore transport from the north and thus starves the North End of sand leading to increased erosion $[46,47]$. The low and narrow characteristics of the North End make it vulnerable to storm waves and overwash and thus erosion [44]. The middle of the island is widest section and the oldest. It includes a substantial amount of maritime forest and is the most stable portion of the island. The southern portion of the island is known as Tom's Cove Hook and is an accretionary spit that has grown $6 \mathrm{~km}$ since the 1800s and continues to develop southward.

The study area for this project, depicted by the red outline Figure 1, encompasses not only Assateague Island but Sinepuxuent and Chincoteague Bay to the west as well as a portion of the surrounding mainland. While the main focus of this study was assessing the impact of Hurricane Sandy on Assateague Island, in order to expand the usefulness of this dataset, the surrounding main lands were included as well since they can have ecological impacts on the resources within Assateague [45]. The mainland is a mixture of both natural and manmade cover types, including forest, shrubland, agriculture and development. Significantly more anthropogenic modifications to the landscape occur on the mainland compared to Assateague Island. While the entire study area was classified and assessed for change, the change detection results will be elaborated on in terms of changes on Assateague Island.

\subsection{Imagery}

For this study, data from two Landsat satellites were used. The pre-Hurricane Sandy imagery was collected by the Landsat 5 Thematic Mapper (TM) sensor while the post-Hurricane Sandy imagery was collected by the Landsat 8 OLI sensor. Hurricane Sandy struck the east coast in October 2012, almost a year after Landsat 5 was decommissioned (November 2011). While Landsat 7 was functional during the time of the hurricane, the failure in the scan line corrector made the data unusable for this study.

Two multi-temporal layer stacks were created, one for before the hurricane and the other for after. Two images were picked for each stack, an early spring, leaf-off image and a late summer image to capture the full phenological differences between classes. All imagery was downloaded from USGS EarthExplorer (http://earthexplorer.usgs.gov). In addition to the seasonal requirements, all imagery had to be cloud free and have near anniversary collection dates within each season in order to avoid substantial differences in phenology between dates. Table 1 shows the collection dates for the imagery used. The summer images were collected within 5 days of each other, however, there was more than a month between the pre and post hurricane early spring imagery. Because Landsat 8 was launched February 2013, the earliest images available are in April 2013. There were no cloud free Landsat 5 images available until 8 March 2011. Ultimately, the summer images were more important for classification and change detection thus it was more important that these images be collected as close to each other as possible. Also, despite the month or so difference in the spring images, the phenology of the vegetation was consistent between the images. 
Table 1. Imagery collection dates.

\begin{tabular}{cccc}
\hline Layer Stack & Sensor & Spring Image & Summer Image \\
\hline Pre-Hurricane Sandy & Landsat 5 TM & 8 March 2011 & 31 August 2011 \\
Post-Hurricane Sandy & Landsat 8 OLI & 14 April 2013 & 5 September 2013 \\
\hline
\end{tabular}

\subsection{Image Processing}

All images were pre-processed prior to performing single-date classifications and change detection using the ERDAS Imagine 2014 software [48]. The imagery for each date and season was first layer stacked and clipped to the study area. The COST correction method [49] was used to radiometrically and atmospherically correct all the images for increased comparability. The original COST correction Equation (1) is shown below along with a table describing the equation variables (Table 2).

$$
\rho=\frac{\left[\pi d^{2}\left(L_{\min }+\frac{D N_{i}\left(L_{\max }-L_{\min }\right)}{D N_{\max }}\right)-\left(L_{\min }+\frac{D N_{\min }\left(L_{\max } L_{\min }\right)}{D N_{\max }}\right)-\left(\frac{.01 d^{2} \cos ^{2} \theta_{z}}{\pi E_{\text {sun }}}\right)\right]}{E_{\text {sun }} \cos ^{2} \theta_{z}}
$$

Table 2. Description of COST parameters.

\begin{tabular}{cc}
\hline Variable & Description \\
\hline$d$ & The sun-earth distance at time of collection \\
$L_{\min }$ and $L_{\max }$ & Spectral radiance calibration factors \\
$\mathrm{DN}_{i}$ & The DN value at pixel $i$ \\
$\mathrm{DN}_{\min }$ & Band specific minimum DN value as determined by user \\
$\mathrm{DN}_{\max }$ & Maximum possible DN value for the data ( ex. 255 for 8 bit) \\
$E_{\text {sun }}$ & Solar spectral irradiance \\
$\theta_{z}$ & Local solar zenith angle ( $90^{\circ}$ - local solar elevation angle) \\
\hline
\end{tabular}

$L_{\min }$ and $L_{\max }$ can be found in the image metadata along with the solar elevation angle needed to calculate $\theta_{z}$. $E_{\text {sun }}$ and $d$ can be found in Chander and Markham [50]. The band specific $\mathrm{DN}_{\min }$ value is found through histogram exploration of each band. The above equation was adjusted in order to perform the correction of the Landsat 8 imagery. Landsat 8 no longer requires that the imagery be processed to radiance before converting to Top-of-Atmosphere reflectance (TOA). Instead, each band can be processed directly to TOA using a constant multiplicative and additive rescaling factor provided in the image metadata. Equation (2) presents the updated COST correction formula for Landsat 8.

$$
\rho=\left(\frac{\left(D N_{i} * 0.00002-0.1\right)}{\cos ^{2} \theta_{z}}\right)-\left(\frac{\left(D N_{\min } * 0.00002-0.1\right)}{\cos ^{2} \theta_{z}}\right)-0.01
$$

Once corrected, derivative layers were generated in order to provide additional information along with the original spectral bands and to improve classification accuracy. Two vegetation index layers were generated for each image, a normalized vegetation index (NDVI) layer and a moisture stress index (MSI) layer. In addition to the vegetation index layers, three tasseled cap (TC) transformation feature layers (brightness, greenness, wetness) were also generated using the transformation coefficients for Landsat 5 and 
Landsat 8 taken from Crist et al. [51] and Baig et al. [52] respectively. The tasseled cap transformations for both sensors make use of the visible band (R, G, and B) as well as the Infrared bands (NIR, SWIR 1, SWIR 2). The Landsat 8 transformations do not utilize the coastal blue band. The corrected imagery and the five derivative layers were then stacked to create a single-date image stack. For each time period, pre-hurricane and post-hurricane, the early spring and late summer images were then stacked together to form the final multi-temporal image for classification.

\subsection{Land Cover Classification}

Land cover classification was carried out in three basic steps. First, reference data were collected for classification training and accuracy assessment. Next a series of classifications were completed. First the new coastal blue band was tested to assess its contribution to the overall classification accuracy. Then, the pre and post hurricane imagery were classified using both the PBC and OBC approaches. In the last step, the accuracy of all maps was calculated and statistically compared to fulfill several of the research objectives.

\subsubsection{Reference Data Collection}

A modified version of the NOAA C-CAP classification scheme [43] was chosen for all the land cover mapping in this study (Figure 2). The original 25 classes were condensed to 10 based upon a priori knowledge of the study area and an examination of previously generated NOAA C-CAP land cover maps. The classes in bold are the final land cover classes used. To improve classification accuracy, four temporary classes were added in order to decrease the spectral variability of the developed and unconsolidated shore classes.

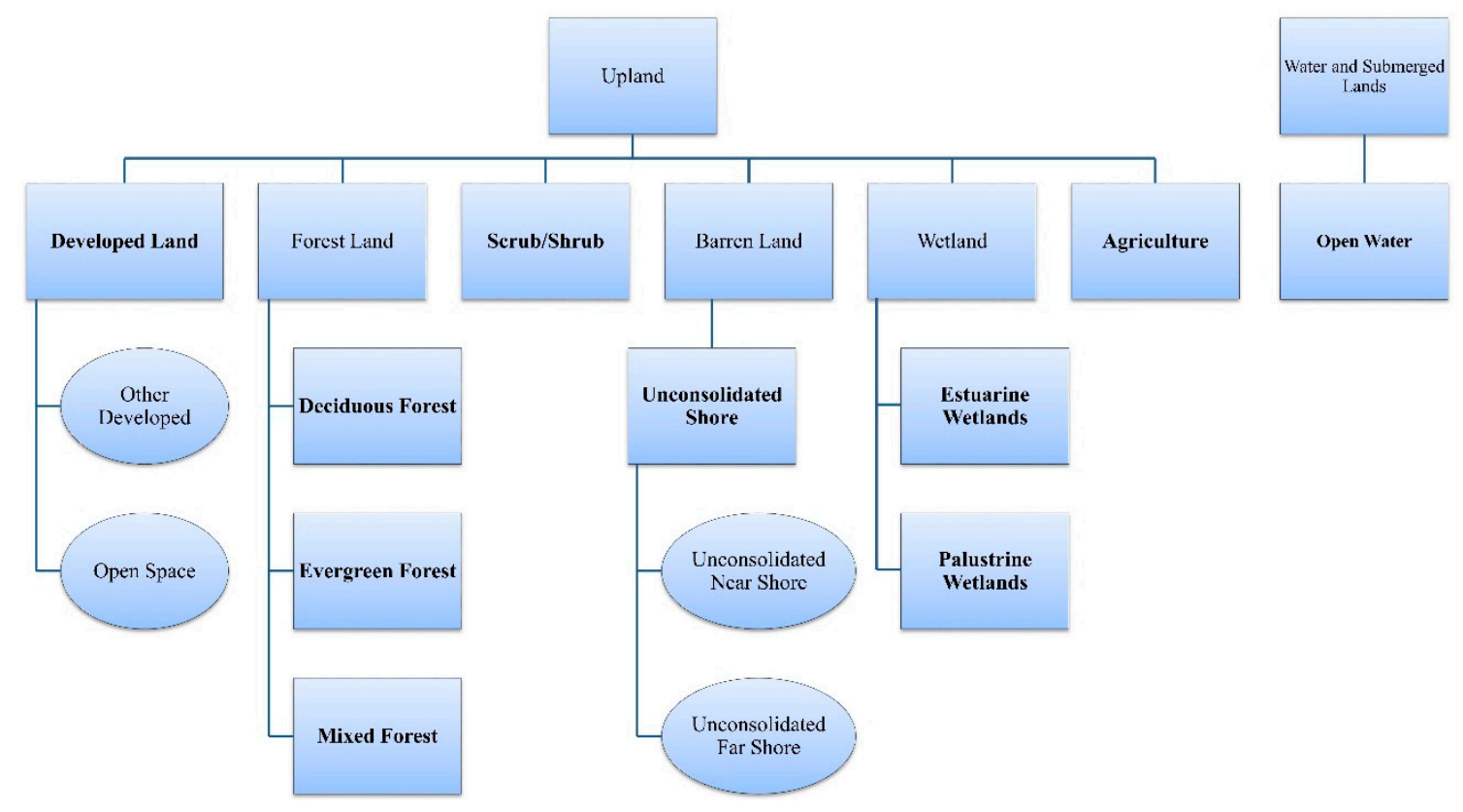

Figure 2. Modified National Oceanic and Atmospheric Administration (NOAA) Coastal Change Analysis Program (C-CAP) classification scheme organized hierarchically. Land cover types in bold, are the cover types of interest in this study. Land cover types in circles represent temporary classes that were aggregated for the final maps. 
Reference data are samples of the land cover classes defined by the classification scheme and are used independently for developing the classification model (i.e. training) and assessing map accuracy. Units that were selected for inclusion as reference data had to meet several requirements outlined in Congalton and Green [53]: (1) the sample had to at least $90 \mathrm{~m} \times 90 \mathrm{~m}$ in size, or $3 \times 3$ Landsat pixels ; (2) the area within each sample had to be spectrally homogenous (only one cover type); (3) a high degree of variation had to be captured for each class; and (4) the samples had to well distributed across the study area in order to avoid spatial autocorrelation.

The goal was to collect 100 samples per land cover class [53]. The reference samples were first carefully inspected using high resolution imagery (2011 and 2012 National Agricultural Inventory Program (NAIP) imagery and Google Earth). Sample unit labels were adjusted as needed. Field reconnaissance was performed between July and August 2014 to confirm the land cover labels of the selected reference data. Following the field reconnaissance, further photo interpretation was conducted to carefully edit the remainder of the reference samples. The final sample totals can be seen in Table 3 . The goal of at least 100 samples was reached for all classes but scrub/shrub and unconsolidated shore. These two classes encompassed a small percentage of the study area and/or occurred in small patches that did not meet the minimum mapping unit. In order to avoid spatial autocorrelation and spectral redundancy, fewer samples were collected [54]. The samples were divided to achieve 50/50split between those samples used for training and those used for accuracy assessment. In the case of scrub/shrub and unconsolidated shore, at least 50 samples were needed to ensure the accuracy assessment was statistically valid for those classes and the remainders were used for training.

Table 3. Number of reference data samples collected for each land cover class.

\begin{tabular}{cccc}
\hline Land Cover Class & Total Samples & Training & Accuracy \\
\hline Agriculture & 106 & 53 & 53 \\
Deciduous Forest & 102 & 52 & 50 \\
Developed & 121 & 71 & 50 \\
Estuarine & 100 & 50 & 50 \\
Evergreen Forest & 100 & 50 & 50 \\
Mixed Forest & 100 & 50 & 50 \\
Open Water & 121 & 61 & 60 \\
Palustrine & 105 & 55 & 50 \\
Scrub/Shrub & 85 & 35 & 50 \\
Unconsolidated Shore & 85 & 35 & 50 \\
\hline
\end{tabular}

\subsubsection{Land Cover Classifications}

All classification processes were performed using Trimble eCognition Developer 9.0 [55]. Prior to classification, an analysis was performed to determine the best parameters for segmentation using the multi-resolution segmentation algorithm. The multiresolution segmentation algorithm requires three user defined parameters, scale, shape, and compactness. While all three play a role in the general shape and size of the polygons, the scale parameter has been found to have a significantly greater control since it ultimately controls the amount of heterogeneity allowed in each segment [56]. Scale values from 2 to 40 were tested to determine the optimal scale parameter while the shape and compactness parameters 
were held at 0.2 and 0.5 respectively. Three methods were used to determine the optimal scale, autocorrelation [57], average local variance [58,59], and a measure that combines both autocorrelation and segment variance known as the objective function [60]. The multiresolution segmentation algorithm was used to perform a series of segmentations with equal weight assigned to all bands in the image. The mean and standard deviation of the summer NIR band was exported along with the final vector for all segmentations. A visual assessment of the "optimal" scale value determined by each method was performed and a final scale was chosen. The same process was used to determine the optimal scale parameter for both the pre and post-hurricane images separately. Due to differences in the sensors that collected each image, it was not appropriate to use the same parameters.

An initial classification was performed on the post-hurricane summer image to assess the contribution of the new coastal blue band to overall classification accuracy. An object based classification was performed using the Random Forest (RF) classifier [61] (called Random Trees in eCognition). After segmenting the image using the optimal parameters, the image segments were intersected with the training data in order to select the training sample segments for the RF classifier. The RF classifier is simple to run and only requires two parameters, the number of trees and the number of randomly selected explanatory variables to select at each split. The number of trees has to be high enough to ensure the out of box (OOB) error, or accuracy of the model, converges (once converged the additional trees neither increases or decreases the OOB error) but the number of selected variables can have an effect on the strength of the individual trees and the correlation between trees [61]. Rodriguez-Galiano et al. [62] found that once convergence is reached, the number of randomly selected variables has very little effect on classification accuracy allowing it to run with little guidence. For this study, each forest was grown using 500 trees and the square root of the number of available features which is the default value for the number of randomly selected variables. While in an object-based environment the model can be trained using a number of object features such as spectral and shape, for this test only the mean spectral values were used to ensure that the RF classifier was only able to choose from the spectral bands while developing the classification model. The classification was performed twice, once with the coastal blue band and once without and the accuracy of each map was calculated and compared. The results determined whether the coastal blue band would remain included in the post-hurricane image.

The post-hurricane and pre-hurricane imagery were then fully classified using both an OBC and PBC with the RF classifier. After segmenting the image using the optimal parameters, the training segments were again selected by intersecting the sample units with the image segments. With a PBC, the model is trained solely on the mean and variance of all the bands and then applied to the unclassified pixels, not the remaining image objects. With an $\mathrm{OBC}$, the model can be trained using a number of object features in addition to the mean band values and variance which is then applied to unclassified segments. The input features used to train the classifier in the object-based environment are given in Table 4.

The open space, other developed, unconsolidated far and near shore classes that were included in the classification as temporary classes in order to break down the spectral variance of the developed and unconsolidated shore classes were aggregated up one level (to unconsolidated shore and developed) following the classification. 


\subsubsection{Accuracy Assessment}

All land cover classifications underwent an accuracy assessment using the independent reference data set. A traditional tally-based error matrix [63] was generated for each classification. The overall accuracy as well as the kappa were all calculated from the error matrix [63]. For each of the object-based classifications, an area-based error matrix [64] was also generated and the overall and kappa were calculated. Several pairwise kappa comparisons took place between the numerous classification results. First, the error matrices for the post-hurricane band testing were compared to assess whether there was a significant difference in classification accuracy when the coastal blue band was included in the classification. Next, a comparison took place between the $\mathrm{OBC}$ and $\mathrm{PBC}$ for both the pre and post-hurricane images to determine whether the classification method produced significantly different accuracies. Finally the matrices of the pre and post-hurricane maps were directly compared for both classification methods (OLI-PBC vs. TM-PBC and OLI-OBC vs. TM-OBC) to determine if there was a significant difference in accuracy using Landsat 8 compared to Landsat 5.

Table 4. Input features for object-based classification.

\begin{tabular}{ccc}
\hline Spectral Feature & Spatial Features & Thematic Features \\
\hline Mean Layer Values & & \\
Standard Deviation & Area & \\
Minimum Pixel Value & Border Length & Min and Maximum \% overlap \\
Maximum Pixel Value & Length & with the National Wetland \\
Mean Difference to Neighbors & Width & Inventory data layer \\
Mean Difference To Super-Objects & Length/Width & \\
Ratio To Super-Objects & & \\
Difference in NDVI and NLWM & & \\
Difference in NIR, SWIR1, SWIR2 & & \\
\hline
\end{tabular}

\subsection{Land Cover Change}

\subsubsection{Univariate Image Differencing}

A univariate image differencing was first carried out using the protocols outlined in Dobson et al. [43]. A pixel-by-pixel subtraction, also known as image differencing, was performed using the pre and post-hurricane NDVI layers and added into eCognition along with the vector boundaries of the object-based post-hurricane classification. The multi-resolution segmentation algorithm was used to segment the NDVI difference layer. During the segmentation, the polygons from the post-hurricane classification acted as boundaries and the segments were then assigned a class according to the thematic polygon it fell within [38] so that class specific change thresholds could be determined as explained in Xian et al. [65]. Change thresholds were determined using a visual assessment with the goal of reducing omission as much as possible especially on the island. Change thresholds were determined for all classes except for estuarine wetland to avoid errors associated with the higher tide in the pre-hurricane summer image. Using the different change thresholds, the segments were classified as either change or no-change based on their mean NDVI difference. 
The next step in the process was to assign the pre-hurricane land cover class to each change area. Prior to this, reference samples that fell within the segments labeled as change were removed and new training samples selected using photointerpretation. The pre-hurricane image and updated training data were then used to classify only those areas that were labeled as change. The classified change areas were merged with the post-hurricane image to form a new complete pre-hurricane image.

\subsubsection{Post Classification Comparison}

In addition, a PCC between the two single-date maps was conducted to compare the results of the univariate image differencing as described above against the results of the PCC. The two single-date maps were overlaid. Areas that exhibited a change in land cover type between dates were considered changed. Since these changed areas were already classified for both dates, no further classification was necessary.

\section{Results}

\subsection{Land Cover Classification}

An initial classification was performed on the post-hurricane summer image to assess the contribution of the new coastal blue band to overall classification accuracy. The RF classifier calculates the importance of each variable in terms of model accuracy automatically while generating the classification model. Table 5 gives the importance value of each band after running the RF classifier on all bands in the summer image. Importance values greater than 0 , indicate that the band was used at a node within the model to generate a decision rule. Since all bands have a value greater than 0 , all bands were used at some point in the development of all the individual decision trees. Higher values indicate that the band has a greater impact on classification accuracy; so for example, the NIR band had the greatest impact on the accuracy of the model. The coastal blue band is at the very bottom of the list indicating that its impact on accuracy of model was the least significant. To test this, two classifications were performed, one with the coastal blue band and the other without. The accuracy of the two maps was calculated and compared using a pairwise kappa comparison. The results are presented in Table 6.

Table 5. Variable importance.

\begin{tabular}{cc}
\hline Band & Importance \\
\hline NIR & 0.108458534 \\
SWIR 1 & 0.101598412 \\
SWIR 2 & 0.101203956 \\
Brightness & 0.099140197 \\
Greenness & 0.092806019 \\
NDVI & 0.089701816 \\
Blue & 0.083893582 \\
Red & 0.076913401 \\
Green & 0.069847479 \\
MSI & 0.066674672 \\
Wetness & 0.062730104 \\
Coastal Blue & 0.047031853 \\
\hline
\end{tabular}


Table 6. Overall accuracy and kappa of coastal blue band test.

\begin{tabular}{ccc}
\hline & Overall Accuracy & Kappa \\
\hline With Coastal Band & $67.57 \%$ & 0.63966 \\
Without Coastal Band & $67.57 \%$ & 0.63964 \\
\hline
\end{tabular}

The overall accuracy of the two maps was exactly the same. Likewise, the kappa values were almost identical (Table 6), and a pairwise kappa comparison $(Z$-score $=0.470)$, confirms that there was no significant difference at the $95 \%$ confidence interval $(Z$-score $<1.96)$. Since no significant difference was found, the coastal blue bands were removed from the post-hurricane image in order to reduce the number of unnecessary features during the single-date classifications.

The pre and post-hurricane imagery were then classified using both a pixel and object-based classification. Figures 3 and 4 are the results of the pixel-based and object-based classification for both of the single-date classifications respectively. There is strong agreement between the two maps created using both methods.

\subsection{Accuracy Assessment}

For each of the maps produced an accuracy assessment was performed. For the object-based maps, both a traditional tally-based error matrix and an area-based error matrix were generated. For the pixel-based classifications, only a tally-based error matrix is appropriate. For each matrix, the overall accuracy was calculated as well as the kappa. A pairwise kappa comparison was then run to compare several of the matrices in order to determine if: (1) there was a significant difference in the accuracy between the Landsat 8 and Landsat 5 maps; and (2) whether there was an improvement in accuracy using the object-based compared to pixel-based classification.

\subsubsection{Single Date Classification Accuracy}

The overall accuracies are summarized in Table 7 along with the kappa and Z statistic for each map. Remember that there is no area-based accuracy assessment for pixel-based classifications. All single-date classifications had overall accuracies greater than $75 \%$ and all kappa values indicate a moderate agreement between the map and the reference data. Additionally, the $\mathrm{Z}$ statistics indicate that all maps were better than a random classification at the $95 \%$ confidence interval ( $Z$ Statistic $>1.96$ ). The overall accuracy and kappa statistics for the area-based maps attained better accuracies compared to the assessment using the tally-based matrix. These higher values for the area-based $v s$. traditional analysis were expected as shown in MacLean and Congalton [64] and Campbell et al. [38]. The overall accuracies between the pre and post hurricane maps were very similar for both methods. The object-based pre-hurricane map did have a slightly higher overall accuracy than the post-hurricane map. Secondly, the overall accuracies were similar for both the pixel-based and object-based classifications, with the object based obtaining a slightly higher accuracy for both dates. 
Pre-Hurricane 2011

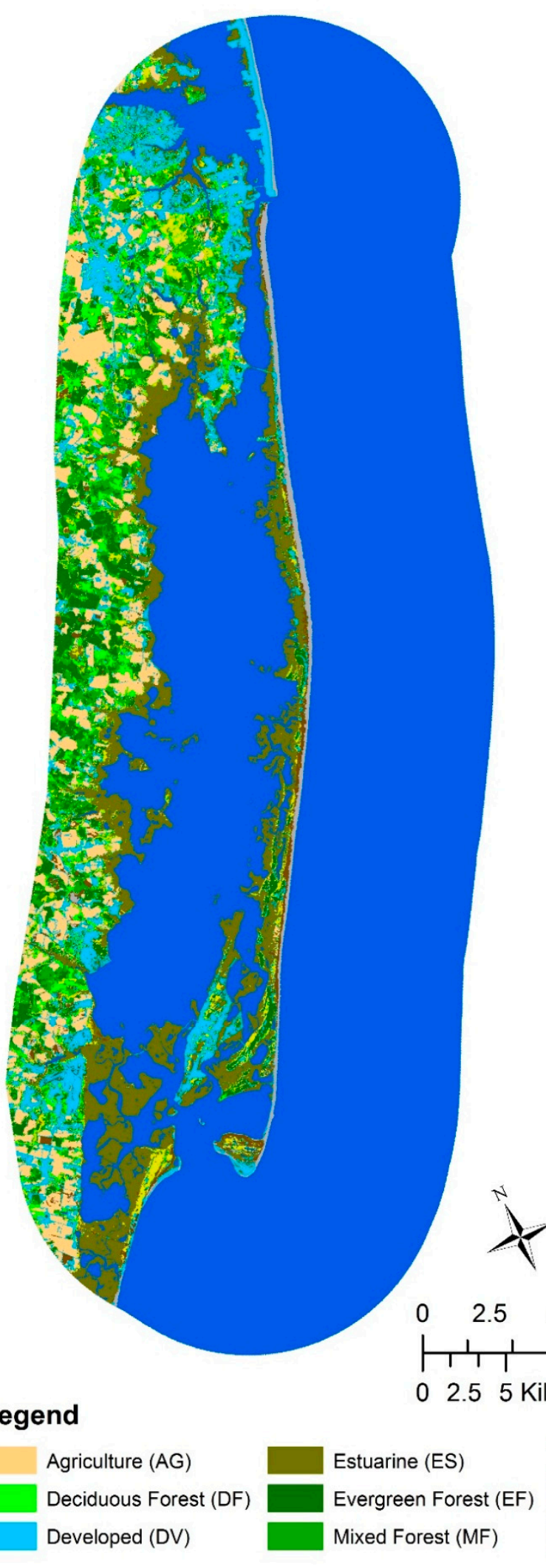

Post-Hurricane 2013

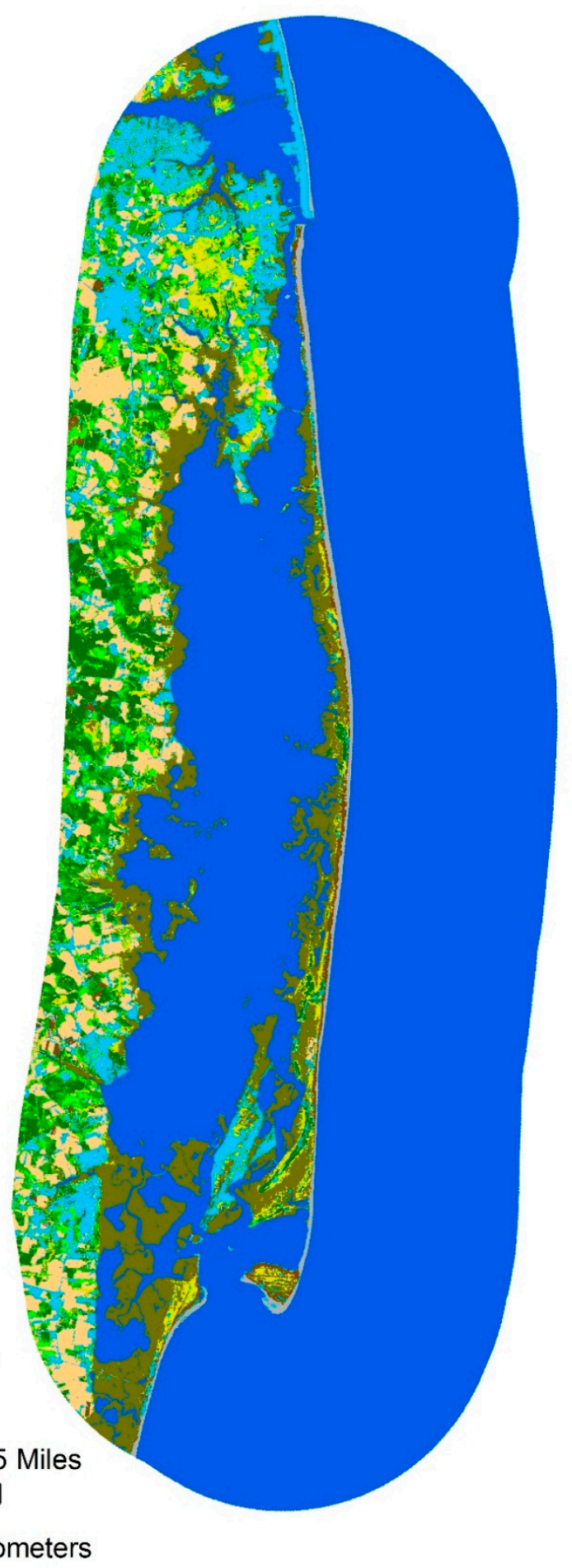

\section{Legend}

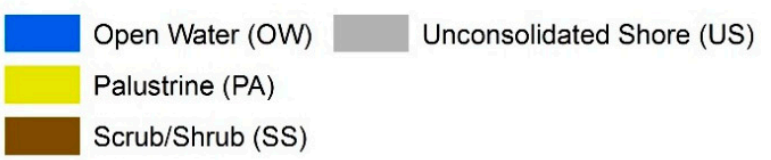

Figure 3. Results of the single-date pixel-based classification. 
Pre-Hurricane 2011

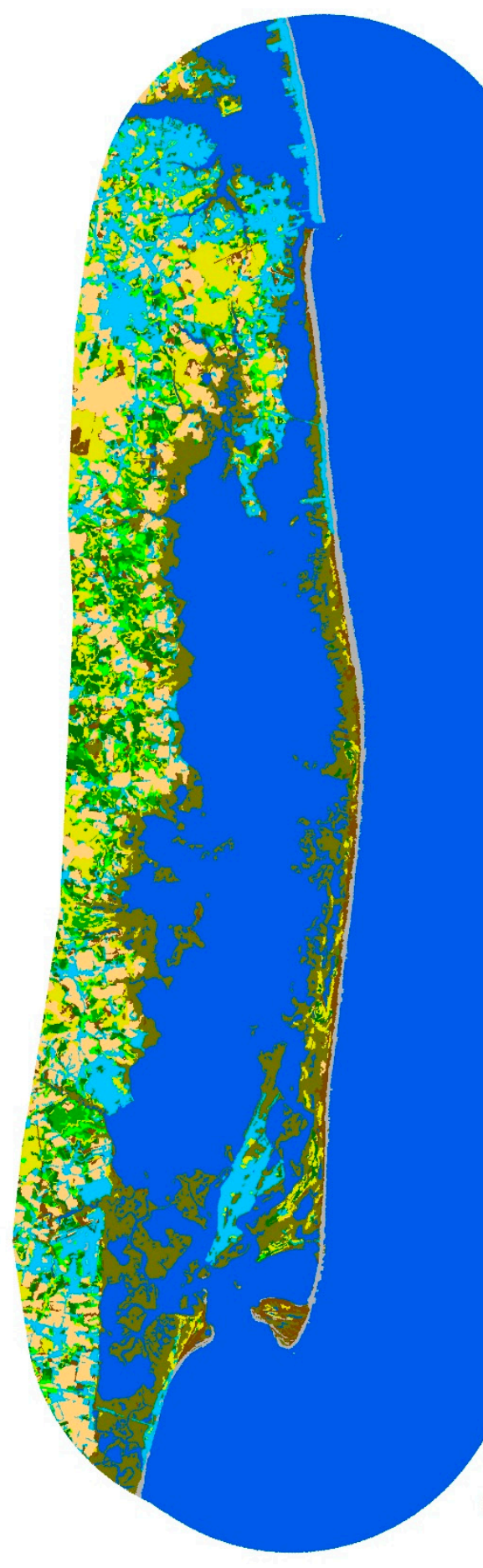

\section{Legend}

Agriculture (AG)

Deciduous Forest (DF)

Developed (DV)
Jimaging 2015, 1

Post-Hurricane 2013

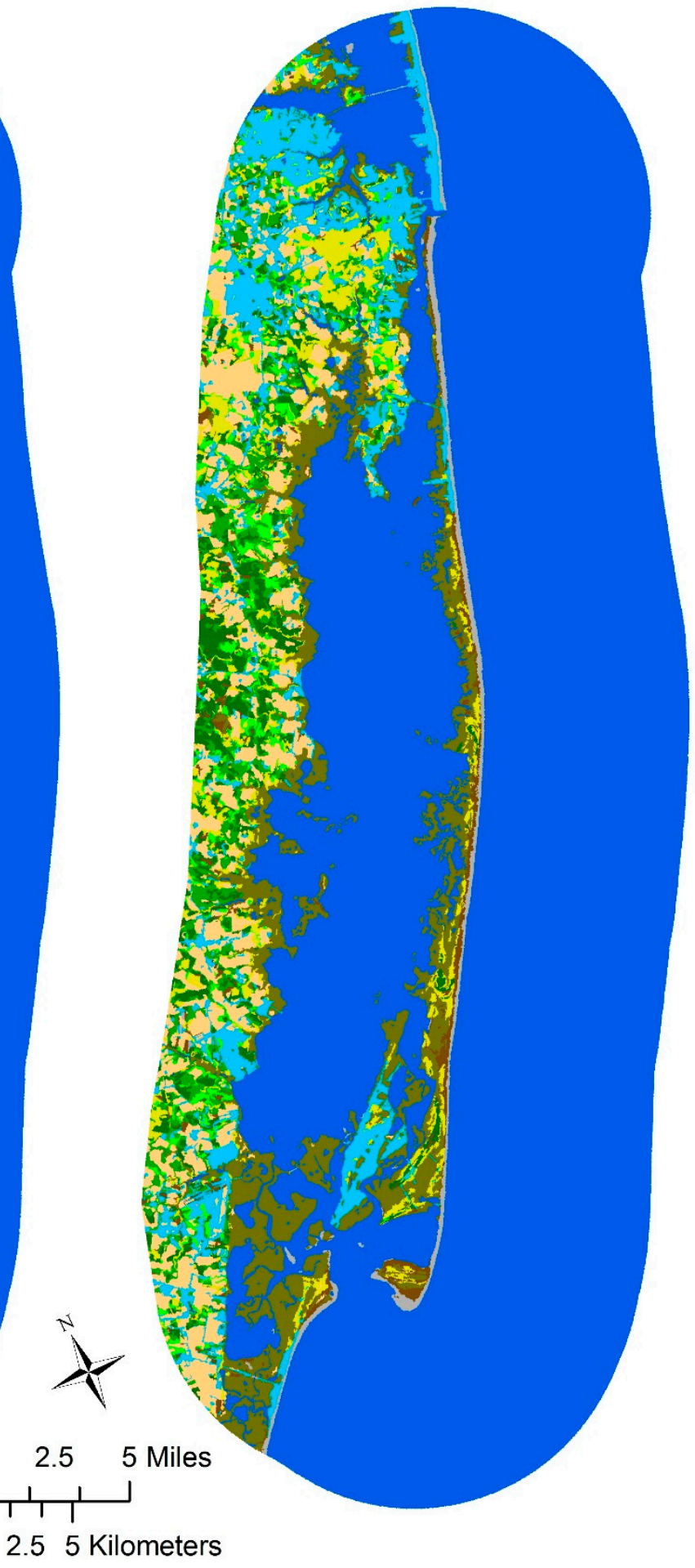

\subsection{Kilometers}

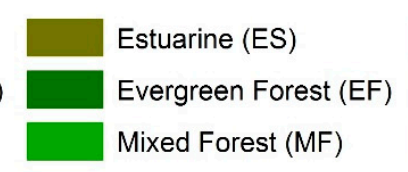

Open Water (OW)

Unconsolidated Shore (US)

Palustrine (PA)

Scrub/Shrub (SS)

Figure 4. Results of the single-date object-based classification. 
Table 7. Summary of single-date classification accuracies.

\begin{tabular}{cccccccc}
\hline \multirow{2}{*}{ Date } & & \multicolumn{3}{c}{ Tally-Based } & \multicolumn{3}{c}{ Area-Based } \\
\hline \multirow{2}{*}{ Pre-Hurricane } & Method & Overall & Kappa & Z Statistic & Overall & Kappa & Z Statistic \\
& Pixel & $78.90 \%$ & 0.765 & 38.325 & $N A$ & $N A$ & $N A$ \\
& Object & $82.64 \%$ & 0.807 & 43.255 & $89.59 \%$ & 0.874 & 144.097 \\
\multirow{2}{*}{ Post-Hurricane } & Pixel & $80.50 \%$ & 0.783 & 40.567 & $N A$ & $N A$ & $N A$ \\
& Object & $81.66 \%$ & 0.796 & 42.217 & $89.79 \%$ & 0.866 & 172.217 \\
\hline
\end{tabular}

Tables 8 and 9 present the user's and producer's accuracies [66] for all of the classifications performed. Most user's and producer's accuracies were close to if not greater than $80 \%$. The most notable exception to this was the palustrine and scrub/shrub class which in all classifications performed had producer's accuracies below 70\% for most cases and in the case of palustrine, the producer's accuracy never got above $60 \%$ with the exception of the area based assessment. User's accuracies for the two classes were better (above $60 \%$ in all cases); however, with the exception of a few cases, they were still lower than the other categories. Palustrine areas were most confused with forested classes and to a lesser extent estuarine wetlands. Scrub/shrub on the other hand was often confused with agriculture and forest classes especially evergreen forests, as well as unconsolidated shore. Forested areas, while performing better than palustrine and scrub shrub, also proved troublesome. Most user's and producer's accuracies were not above $80 \%$; however, they do not drop below $60 \%$. One aspect that was common for all three forest classes in all cases was that many samples were incorrectly classified as palustrine or another forested class.

Table 8. User's (UA) and producer's (PA) accuracies for pre-hurricane classifications using object-based (OBC) and pixel-based (PBC) classification methodology.

\begin{tabular}{ccccccc}
\hline & \multicolumn{2}{c}{ PBC } & \multicolumn{3}{c}{ OBC } \\
& \multicolumn{2}{c}{ Tally-based } & \multicolumn{2}{c}{ Tally-based } & \multicolumn{2}{c}{ Area-based } \\
& UA & PA & UA & PA & UA & PA \\
Agriculture & $100.00 \%$ & $84.00 \%$ & $97.87 \%$ & $92.00 \%$ & $98.12 \%$ & $92.08 \%$ \\
Deciduous Forest & $70.31 \%$ & $90.00 \%$ & $74.55 \%$ & $82.00 \%$ & $78.48 \%$ & $84.03 \%$ \\
Evergreen Forest & $66.67 \%$ & $84.00 \%$ & $82.22 \%$ & $74.00 \%$ & $85.65 \%$ & $79.55 \%$ \\
Mixed Forest & $72.41 \%$ & $84.00 \%$ & $82.98 \%$ & $78.00 \%$ & $82.02 \%$ & $80.94 \%$ \\
Developed & $65.75 \%$ & $96.00 \%$ & $84.21 \%$ & $96.00 \%$ & $84.29 \%$ & $98.81 \%$ \\
Open Water & $100.00 \%$ & $98.21 \%$ & $96.49 \%$ & $98.21 \%$ & $99.69 \%$ & $99.80 \%$ \\
Estuarine & $90.74 \%$ & $98.00 \%$ & $73.77 \%$ & $90.00 \%$ & $84.64 \%$ & $96.30 \%$ \\
Palustrine & $60.00 \%$ & $22.64 \%$ & $73.17 \%$ & $56.60 \%$ & $68.85 \%$ & $60.87 \%$ \\
Scrub/Shrub & $81.25 \%$ & $54.17 \%$ & $71.43 \%$ & $72.92 \%$ & $75.80 \%$ & $68.64 \%$ \\
Unconsolidated Shore & $84.78 \%$ & $78.00 \%$ & $89.58 \%$ & $86.00 \%$ & $92.08 \%$ & $85.33 \%$ \\
\hline
\end{tabular}

\subsubsection{Kappa Analysis}

A pairwise kappa analysis was performed after the creation of the error matrices to assess whether there was a significant difference between the pre and post hurricane images (Landsat $8 v s$. Landsat 5) as well as the object-based and pixel-based classifications. For the pre and post hurricane map 
comparison, the results were compared for both the object-based and pixel-based classifications, including the error matrices for the area-based assessment for the object based classification. For the object-based $v s$. pixel-based comparison, only the tally-based error matrices were compared for each method since an area-based assessment is not performed on a pixel-based map. Tables 10 and 11 present the results of the pre $v s$. post hurricane analysis and the object $v s$. pixel-based analysis respectively.

Table 9. User's (UA) and producer's (PA) accuracies for post-hurricane classifications using object-based (OBC) and pixel-based (PBC) classification methodology.

\begin{tabular}{ccccccc}
\hline & \multicolumn{2}{c}{ PBC } & \multicolumn{3}{c}{ OBC } \\
\hline Land Cover Class & \multicolumn{2}{c}{ Tally-based } & \multicolumn{2}{c}{ Tally-based } & \multicolumn{2}{c}{ Area-based } \\
& UA & PA & UA & PA & UA & PA \\
Agriculture & $90.38 \%$ & $88.68 \%$ & $89.29 \%$ & $94.34 \%$ & $91.41 \%$ & $95.31 \%$ \\
Deciduous Forest & $74.07 \%$ & $80.00 \%$ & $72.22 \%$ & $78.00 \%$ & $79.94 \%$ & $78.65 \%$ \\
Evergreen Forest & $69.09 \%$ & $76.00 \%$ & $78.26 \%$ & $72.00 \%$ & $75.64 \%$ & $76.17 \%$ \\
Mixed Forest & $73.47 \%$ & $72.00 \%$ & $64.58 \%$ & $62.00 \%$ & $66.84 \%$ & $68.51 \%$ \\
Developed & $71.93 \%$ & $82.00 \%$ & $85.45 \%$ & $94.00 \%$ & $87.88 \%$ & $97.95 \%$ \\
Open Water & $100.00 \%$ & $98.33 \%$ & $100.00 \%$ & $98.33 \%$ & $100.00 \%$ & $99.61 \%$ \\
Estuarine & $88.68 \%$ & $94.00 \%$ & $83.93 \%$ & $94.00 \%$ & $90.36 \%$ & $96.08 \%$ \\
Palustrine & $60.87 \%$ & $50.91 \%$ & $66.00 \%$ & $60.00 \%$ & $71.53 \%$ & $68.85 \%$ \\
Scrub/Shrub & $80.00 \%$ & $64.00 \%$ & $80.00 \%$ & $64.00 \%$ & $79.68 \%$ & $55.12 \%$ \\
Unconsolidated Shore & $92.45 \%$ & $98.00 \%$ & $90.74 \%$ & $98.00 \%$ & $94.44 \%$ & $99.04 \%$ \\
\hline
\end{tabular}

The kappa analysis comparing the pre and post hurricane images indicates that there is no significant difference between the two maps for both the pixel and object-based classifications since all $\mathrm{Z}$ test statistics were less than 1.96. The kappa analysis comparing the object-based and pixel-based classifications also indicates no significant difference between the two methods for either map.

Table 10. Kappa analysis comparing pre and post hurricane error matrices.

\begin{tabular}{ccc}
\hline Method & Accuracy Assessment Type & Z Test Statistic \\
\hline \multirow{2}{*}{ Object } & Tally-based & 0.413 \\
& Area-based & 0.950 \\
\hline Pixel & Tally-based & 0.640 \\
\hline
\end{tabular}

* Significant at 95\% confidence level.

Table 11. Kappa analysis comparing object-based $v s$. pixel-based classifications error matrices.

\begin{tabular}{cc}
\hline Classification & Z Test Statistic \\
\hline Pre-Hurricane & 1.52 \\
Post-Hurricane & 1.11 \\
\hline
\end{tabular}

* Significant at $95 \%$ confidence level.

\subsection{Land Cover Change Detection and Classification}

With the vector results of the post-hurricane classification included to act as boundaries, a within-class segmentation was performed with the full weight placed on the results of the image 
differencing between the post-hurricane and pre-hurricane NDVI. It was then possible to develop class specific change threshold values using the class specific change means and standard deviations of the resulting segments. Change thresholds were calculated by multiplying the standard deviation by an adjustable parameter and then adding and subtracting that value from the mean. The appropriate adjustable parameter and thus change thresholds for each class was determined by testing several parameter values and visually assessing how well the resulting thresholds detected change within each class. A parameter value of 1.5 was found to work best for all classes except for unconsolidated shore and scrub/shrub which required a value of 1 to detect all changes. Using the calculated thresholds, the objects within the image were classified as either change or no-change. Areas labeled as change were then classified with a pre-hurricane class and merged with the post-hurricane results.

Following the completion of the UID methodology, a PCC was also carried out between the two single date maps. The pre and post hurricane map were unioned and areas with two different land cover labels were classified as change. Figure 5 shows the difference between the areas classified as change and no change using the two change detection methods. The PCC classified $8.98 \%$ of the study area as change while the UID classified $0.339 \%$ of the area. It is important to note that while developing change thresholds for the UID, change was not detected for estuarine wetlands in order to reduce errors associated with the tide. For the PCC, the two maps were simply overlaid as they were. The results from both change detection methodologies were overlaid to identify and measure spatial agreement between areas labeled as change (Figure 6). Combined, 17275.59 ha were classified as change and of this area, 523.53 ha were identified as change by both the PCC and UID (shown in green in Figure 6). The area of agreement includes $80.63 \%$ of the area identified as change by the UID methodology and $3.05 \%$ of the area identified as change by the PCC.

Given the high percentage of area identified as change by the PCC, some supplementary evaluations were conducted to assess the results of the PCC. The PCC conducted previously was performed using the object based maps which, when overlaid, can create slivers due to differences in object boundaries between dates. A PCC was performed on the results of the pixel-based classifications, eliminating slivers, and was compared to the object-based PCC. The percentage of the study area classified as change by the pixel-based PCC was $8.59 \%$, only a $0.3 \%$ drop compared to the object-based PCC. Additionally, the effect of aggregating land cover classes on the amount of area classified as change was investigated. Two aggregations and PCCs were performed. The first involved aggregating mixed, evergreen, and deciduous forest up one level and reclassifying them as forest and then performing a PCC with the reclassified maps. The second involved aggregating estuarine and palustrine up to wetland in addition to the aggregation of the forest classes and performing a PCC for a second time. Class aggregation was done for the object-based and pixel-based classifications. The results are shown in Table 12. It should be noted that the percent difference in change area represents the percent difference in total area classified as change after performing an aggregation and PCC compared to total area classified as change using the PCC with the original land cover maps (all 10 classes with no aggregation). Thus there is no percent difference in change area for the original 10 classes (shown as NA in table) 


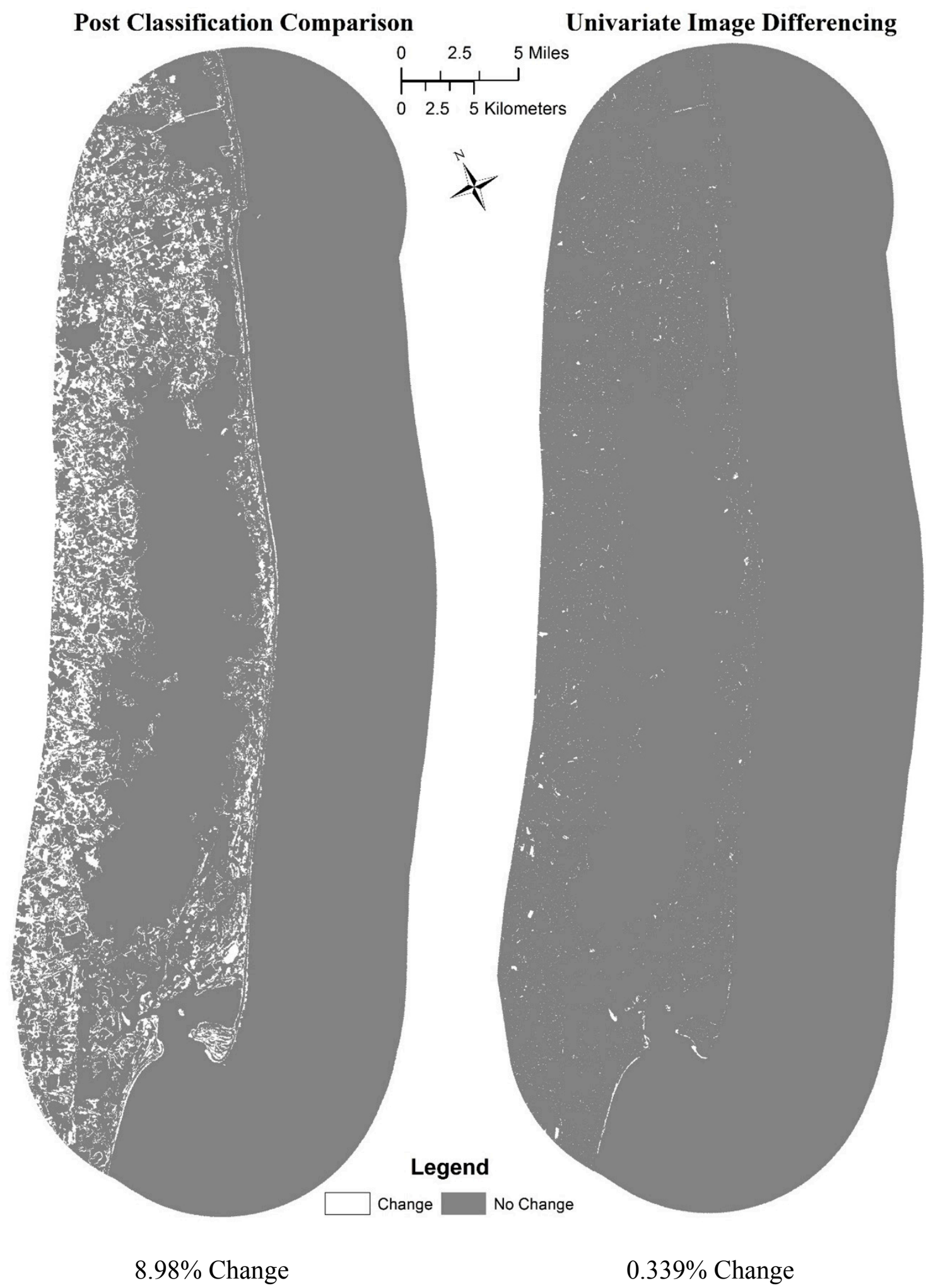

Figure 5. Areas of change and no-change as detected by the univariate image difference and post classification comparison (PCC). Percent change under each map represents percentage of study area classified as change by each method. 


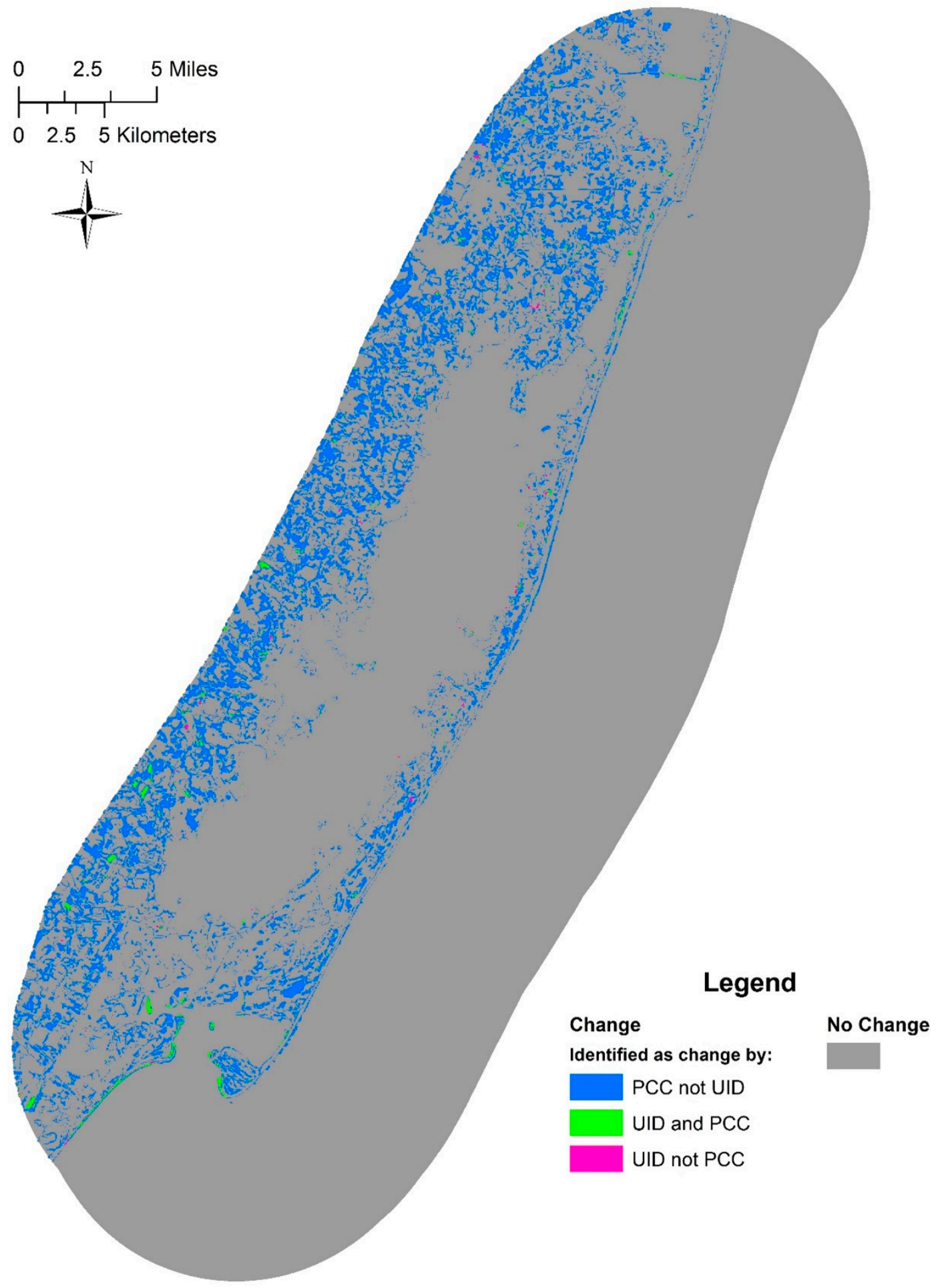

Figure 6. Overlay of the areas classified as change by the Post Classification Comparison (PCC) and Univariate Image differencing (UID). Areas in green represent agreement between methods while blue and pink are areas identified as change by one method but not the other. 
Table 12. Results of aggregating land cover classes on PCC change detection.

\begin{tabular}{|c|c|c|c|}
\hline \multicolumn{4}{|c|}{ Object-Based PCC } \\
\hline Class Aggregation & $\begin{array}{c}\text { Total Area } \\
\text { Classified As } \\
\text { Change (ha) }\end{array}$ & $\begin{array}{c}\text { Percentage of Study } \\
\text { Area Classified As } \\
\text { Change }\end{array}$ & $\begin{array}{l}\text { Percent Difference in } \\
\text { Change Area * }\end{array}$ \\
\hline Original Classes & $1,7149.86$ & $8.98 \%$ & NA \\
\hline Aggregate Forest Classes & $1,5030.63$ & $7.87 \%$ & $12.36 \%$ \\
\hline $\begin{array}{l}\text { Aggregate Forest and } \\
\text { Wetland Classes }\end{array}$ & $1,4151.87$ & $7.41 \%$ & $17.48 \%$ \\
\hline \multicolumn{4}{|c|}{ Pixel-Based PCC } \\
\hline Class Aggregation & $\begin{array}{c}\text { Total Area } \\
\text { Classified As } \\
\text { Change (ha) }\end{array}$ & $\begin{array}{c}\text { Percentage of Study } \\
\text { Area Classified As } \\
\text { Change }\end{array}$ & $\begin{array}{l}\text { Percent Difference in } \\
\text { Change Area * }\end{array}$ \\
\hline Original Classes & $1,6409.16$ & $8.59 \%$ & NA \\
\hline Aggregate Forest Classes & $1,4236.65$ & $7.45 \%$ & $13.24 \%$ \\
\hline $\begin{array}{l}\text { Aggregate Forest and } \\
\text { Wetland Classes }\end{array}$ & $1,3515.3$ & $7.07 \%$ & $17.64 \%$ \\
\hline
\end{tabular}

* Compared to the total area classified as change using the original 10 land cover classes.

For both the object and pixel-based PCC, by aggregating the classes, the total area classified as change dropped. There was a $12.36 \%$ drop in the total area classified as change just by aggregating the forest classes together for the object-based PCC. A similar drop was seen with the pixel-based PCC. The drop was slightly higher by adding in the aggregated wetland classes. While there was a drop in the total area classified as change, the percent change still remains higher than that see with the UID.

Table 13. Land cover totals and area difference in hectares for the entire study area after using univariate image differencing to generate the pre-hurricane map. A negative difference indicates a decrease in the total area for that class between dates.

\begin{tabular}{ccccc}
\hline & Pre-Hurricane & Post-Hurricane & Difference (ha) & Percent Change \\
\hline Deciduous Forest & 5.67 & 5.67 & 0.00 & $0.000 \%$ \\
Developed & 199.53 & 199.80 & 0.27 & $0.001 \%$ \\
Estuarine & 4043.71 & 3966.58 & -77.13 & $0.417 \%$ \\
Evergreen Forest & 273.24 & 274.50 & 1.26 & $0.007 \%$ \\
Open Water & $1,0457.08$ & $1,0500.19$ & 43.11 & $0.233 \%$ \\
Palustrine & 1040.67 & 1048.59 & 7.92 & $0.043 \%$ \\
Scrub/Shrub & 1100.70 & 1088.28 & -12.42 & $0.067 \%$ \\
Unconsolidated Shore & 1368.77 & 1405.76 & 36.99 & $0.200 \%$ \\
& & & Total $=$ & $0.969 \%$ \\
\hline
\end{tabular}


Tables 13 and 14 give the land cover totals and area differences on Assateague Island using the UID and PCC respectively. Most of these changes within the island are expected to have been a result of Hurricane Sandy since development is not common here. As can be seen in Table 13, the greatest impact was to estuarine, scrub/shrub, unconsolidated shore, and open water. Both scrub/shrub and estuarine experienced a decrease in area while unconsolidated shore experiences a considerable increase. The results after performing the PCC (Table 14) exhibit similar trends with the addition of palustrine wetlands that saw the largest increase between dates and unconsolidated shore which saw a decrease. There is very little agreement on the direction (increase or decrease) and magnitude of change.

Table 14. Land cover totals and area difference in hectares for Assateague Island using PCC.

A negative difference indicates a decrease in the total area for that class between dates.

\begin{tabular}{ccccc}
\hline & Pre-Hurricane & Post-Hurricane & Difference (ha) & Percent Change \\
\hline Deciduous Forest & 6.39 & 5.67 & -0.72 & $0.004 \%$ \\
Developed & 193.68 & 199.80 & 6.12 & $0.033 \%$ \\
Estuarine & 4000.57 & 3966.58 & -33.99 & $0.184 \%$ \\
Mixed Forest & 9.90 & 0.00 & -9.90 & $0.054 \%$ \\
Evergreen Forest & 284.85 & 274.50 & -10.35 & $0.056 \%$ \\
Open Water & $1,0644.9$ & $1,0500.19$ & -144.71 & $0.783 \%$ \\
Palustrine & 674.28 & 1048.59 & 374.31 & $2.024 \%$ \\
Scrub/Shrub & 1112.58 & 1088.28 & -24.30 & $0.131 \%$ \\
Unconsolidated Shore & 1562.22 & 1405.76 & -156.46 & $0.846 \%$ \\
& & & Total $=$ & $4.11 \%$ \\
\hline
\end{tabular}

\section{Discussion and Conclusions}

The main goal of this study was to quantify and qualify the type and amount of land cover change that occurred on Assateague Island as a result of Hurricane Sandy. With hurricane change detection established as the overarching goal, it was possible to perform several additional assessments; comparing the performance of Landsat 8 to Landsat 5, and object $v s$. pixel-based classification. Several findings resulted from this study and are discussed below.

\subsection{Landsat 5 vs. Landsat 8}

In this study the addition of the coastal blue band as well as the improvements in the Landsat OLI sensor (radiometric resolution and spectral bandwidths) were tested. First, the difference in accuracy between classifications was compared with and without the coastal blue band. The coastal blue band was the only new band assessed as the cirrus band is comprised of wavelengths that are almost completely absorbed by atmospheric moisture, providing little additional information. Additionally, the quality control band does not contain any spectral information and is instead used to assess the quality of the imagery. The coastal blue band was not found to improve the accuracy of the classification. The result is understandable given the placement of the band in the electromagnetic spectrum. In upland land cover classification, the visible bands often do not provide important information necessary to distinguish one cover type from another; the infrared bands are better suited to that end. Liu et al. [67] also found that both the coastal blue band and the new cirrus band had little effect on the derivations of the tassel cap 
components and their ability to classify land cover types. However, because this band is comprised of very narrow wavelengths, it would better be able to penetrate water and improve bathymetric studies or studies investigating subaquatic vegetation. In addition, its placement will make it important for detecting atmospheric conditions and improving atmospheric correction because it is highly scattered.

With the increase in radiometric resolution, it was expected that the classification accuracy for the post-hurricane map (Landsat 8) would be significantly better than the pre-hurricane (Landsat 5) maps due to the improved separability of spectrally similar classes and improvement in bandwidth ranges. Using several pairwise kappa analyses, however, it was found that there was no significant difference in classification accuracy for either the object-based or pixel-based classifications.

It is possible that the differences in the training and accuracy samples between maps may have had an impact. Each image underwent a separate segmentation and then the segments were intersected with the reference unit centroids. It is not likely that the same size and shaped segments were generated, thus each classification was trained with and applied to slightly different segments which could alter the results. Furthermore, it is possible that the classification scheme used was not detailed enough for the higher radiometric resolution to make a difference in the classification accuracy. The NOAA C-CAP classification scheme used here was designed to be used with 8 bit Landsat data collected by the TM and Enhanced Thematic Mapper (ETM+) sensors, and has been successfully used to classify these cover types for a number of years with a high level of accuracy. There may be enough information stored in the 8 bit imagery to distinguish the spectrally similar classes. Additional studies would need to be conducted using more detailed schemes to determine when the improved radiometric resolution would be a benefit for land cover classification. It is important to keep in mind though that the $30 \mathrm{~m}$ spatial resolution may limit how detailed one can get. Furthermore, the enhanced radiometric resolution may benefit studies where biological parameters are being measured from the imagery as demonstrated in Dube and Mutanga [20] who found Landsat 8 OLI data provided better estimates of above ground biomass compared to Landsat 7 ETM+.

\subsection{Object vs. Pixel-Based Classification}

While object-based classification has been shown to improve the classification accuracy of high-resolution imagery, with moderate resolution imagery the benefits have not been clear. One of the objectives of this study was to further investigate this relationship by comparing a pixel-based and object-based classification using the same training data and classification algorithm, which has not commonly been done in previous investigations. No significant difference between the object-based and pixel-based classifications for both the pre-hurricane and post-hurricane imagery was found which is similar to conclusions reached in other studies utilizing medium resolution imagery $[39,40,68]$.

One of the main advantages of OBIA that allows it to perform well is its ability to reduce the spectral variability within a class and thus confusion between classes. If there was not much within class spectral variability to begin with, however, then the benefits of OBIA would be diminished. It was pointed out in Campbell et al. [38] that a $30 \mathrm{~m}$ Landsat pixel is sizable and could be considered an image object in-and-of itself and if the classification scheme was more detailed, then a single pixel may reduce the spectral noise enough to allow the pixel to be classified accurately. On the other hand, if the classes were very broad, then one would expect significantly more within-class spectral variability. For example, the 
class forest would include the spectral characteristics of both deciduous and evergreen forest or developed would include the characteristics of a multitude of objects such as grass, trees, roof tops, pavement, etc. With broad classes, the reduction in noise may actually increase the classification accuracy, especially for more heterogeneous classes.

\subsection{Land Cover Change}

One of the major objectives of this study was to quantify the land cover change that occurred on the island as a result of Hurricane Sandy. The UID approach was implemented to detect changes and then update the post-hurricane map in order to generate a more consistent pre-hurricane map. From there, the land cover totals and differences were calculated. The PCC was also implemented to detect where change had occurred and the type of change using the information provided in both single-date maps.

Changes across the entire study area were minimal. By percent change, the UID labeled $0.336 \%$ of the study area as change while the PCC labeled 8.98\%. A minimal amount of change was expected given the time frame of the study; however, the PCC method detected significantly more. There was some agreement between the two methods. The UID methodology relies on the change in spectral reflectance to detect change, not a difference in thematic labeling which is dependent on the quality of the classification. Of the area classified as change using the UID, $80 \%$ of it was detected as change by the PCC method indicating that the PCC was able to detect real land cover changes in the study area, however, a great deal of false change was detected as well.

Two factors could explain why such a substantial difference was seen between the change detection methodologies. First, an object-based PCC suffers from the effects of slivers. When different sets of imagery undergo separate segmentations, it is rare that the resulting segments will exhibit the same geometry due to differences in the environmental conditions when the images were captured or misregistration [69]. When overlaid, differences in the edges of the segments create slivers which can lead to additional change errors. The second factor is thematic errors. The PCC method relies upon the accuracy of the single-date maps. Errors in the maps will appear as erroneous changes and can occur in both object-based and pixel-based PCC. In this case, two segments representing the same feature may have different class labels because of the classification process, which results in a change error.

The object-based PCC was compared to the pixel-based PCC to assess the possible contribution of slivers to the total change area detected by the PCC. Both methods detected a similar amount of change with the pixel-based detecting slightly less, so slivers were perhaps a minimal component to the objectbased PCC. The differences in thematic labeling were investigated further by aggregating classes prior to performing the PCC (see Table 12). By simply aggregating mixed, deciduous, and evergreen forest together, the total area classified as change dropped by $12.36 \%$ and $13.24 \%$ for the object-based and pixel-based maps respectively. One would not expect the composition of a forest to change within two years, so this difference in area was due to differences in the labeling of these forested polygons and pixels between maps. By aggregating the wetland classes, an even greater drop was observed. The result of this investigation suggests that change detection errors could be reduced by simply aggregating classes up to a higher level in the classification scheme. Nevertheless, even after aggregating the wetland and forest classes, the percentage of the study area classified as change was still over $7 \%$ for both PCCs indicating that a number of labeling errors still exists. 
The object-based univariate image differencing method applied here has the advantage of detecting changes due to spectral differences between dates and not because of differences in thematic labeling. Furthermore, by enforcing the boundaries of the post-hurricane map during the segmentation of the difference image, internal adjustments could be made to those segments that experienced real change. Had the difference image been segmented without the enforced boundaries, when updating the post-hurricane map, differences between the changed objects and the base map would result in silvers as demonstrated in McDermid et al. [70]; however, there would be significantly fewer compared to the PCC since only the overlap between the change objects and the base map occurs, Enforcing the boundaries did not eliminate spurious slivers altogether. Boundary errors in the post-hurricane map still resulted in slivers, some only a few pixels in size. Fuzzy boundaries between cover types also make it difficult to accurately delineate features

While change was measured for the entire study area, this paper focuses mainly on the results seen within Assateague Island. While the PCC estimated a greater amount of change within the island, there were some consistent results. Estuarine, scrub/shrub, and unconsolidated shore experiences the greatest changes on the island itself. Estuarine and scrub/shrub both saw decreases. Surprisingly, unconsolidated shore saw a significant decrease with the PCC compared to the UID that showed an increase. It is probable that this is due to the decrease in shoreline detected by the PCC and not with the UID. It is difficult to say whether this was real change or not as it could have been explained by differences in the tide.

While changes on the island were minimal, where they occurred is consistent with the structure of the island itself. Most of the change detected within the northern $10 \mathrm{~km}$ of the island, known as the North End, as well as the southernmost hook known as Tom's Cove Hook (Figure 7). The center of the island experienced almost no change with the exception of a few small overwash fans. The North End much lower relative to the rest of the island and does not have a continuous, high dune to protect the vegetation on the side closest to the bay. These characteristics leave the area very susceptible to overwash which carries sand from the ocean onto the mainland. The North End saw an increase in unconsolidated shore due to a large overwash fan burying estuarine wetland and scrub/shrub areas that are close to the ocean due to this area being so narrow. Tom's Cove Hook on the other hand is an accretionary spit. Long shore transport carries sand from the northern portion of the island south where it accumulates at the spit. The hook saw a significant increase in the southern tip of the spit following the hurricane as well as a loss of a very small amount of estuarine and scrub/shrub habitat that was buried by a small overwash fan. In general the location and type of change detected on the island is consistent with its ecology and topography.

It is important to note that these results should be taken as estimates. First, it was not possible to collect reference data on the actual changes that occurred within this time span thus it was not possible to assess the accuracy of these results. Second, a visual assessment was undertaken to choose change threshold parameters. While more objective methods exist to develop change thresholds, since change was expected to be minimal and the study area was small, a visual assessment was conducted instead. The goal was to reduce omission, thus overestimation of change was preferred rather than under estimation. It is possible that more change was detected than had actually occurred. Differences in tide between the two dates may have also played a role in the final results. While estuarine habitat was not included in the change detection process in order to reduce possible errors, a great deal of unconsolidated shore and open water changes were classified as estuarine in the pre-hurricane map leading to a higher decrease in estuarine wetlands than was actually experienced. 
(a)

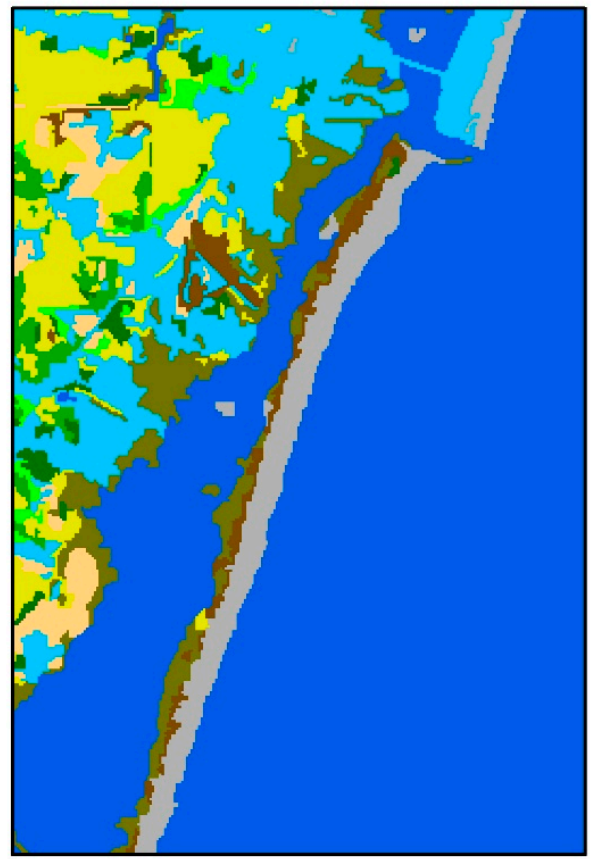

(c)

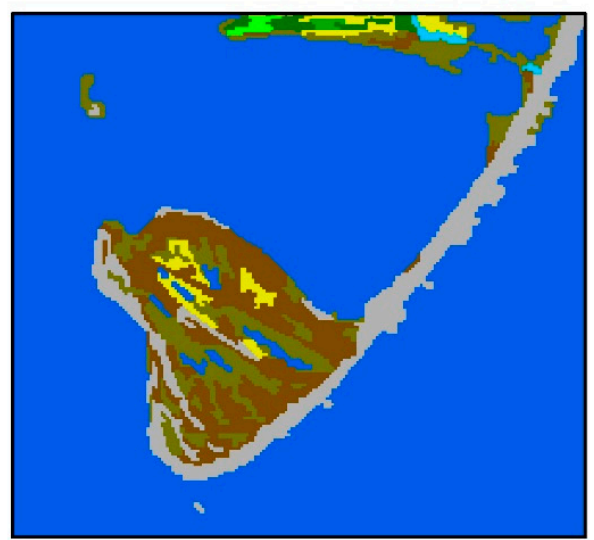

(b)

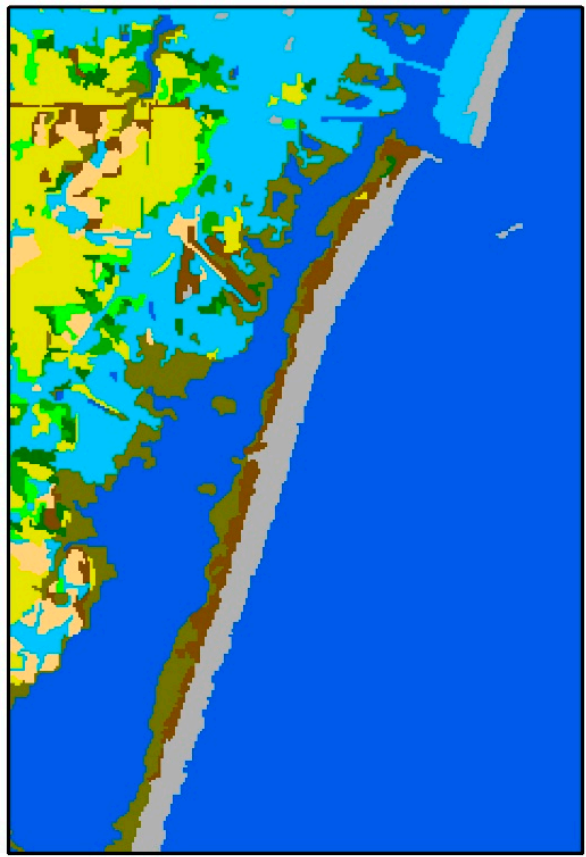

(d)

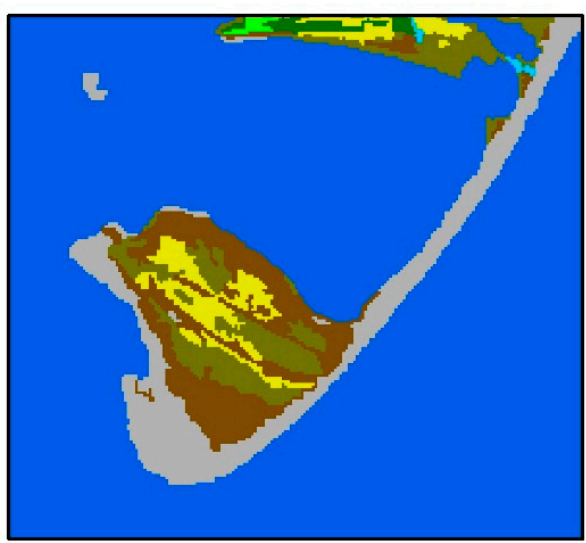

\section{Legend}

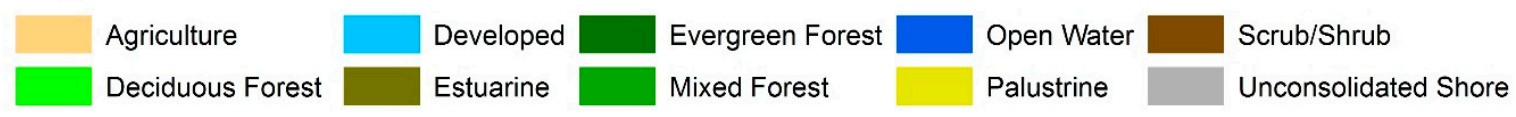

Figure 7. The North End before (a) and after (b) Hurricane Sandy. Tom's Hook Cove before (c), and after (d) the hurricane.

This study was limited to detecting large area changes. Given the spatial resolution of the Landsat data, it was not possible to detect changes smaller than $30 \mathrm{~m} \times 30 \mathrm{~m}$ in size. Higher spatial resolution data would be needed to detect smaller changes but it was not available for the entire study area. Additionally, the use of Landsat data allows for this analysis to be integrated with pre-existing land cover maps and with the data being freely available, these maps can be updated as needed.

\section{Acknowledgments}

Partial funding was provided by the New Hampshire Agricultural Experiment Station. This is Scientific Contribution Number 2628. This work was supported by the USDA National Institute of Food and Agriculture McIntire-Stennis Project 1002519. This project was also supported in part by Grant 
Number G14AP00002 from the Department of the Interior, United States Geological Survey to AmericaView. Its contents are solely the responsibility of the authors; the views and conclusions contained in this document are those of the authors and should not be interpreted as representing the opinions or policies of the U.S. Government. Mention of trade names or commercial products does not constitute their endorsement by the U.S. Government. Furthermore, we wish to extend our thanks and appreciation to the staff at Assateague Island National Seashore for their support and assistance during this project.

\section{Author Contributions}

Heather Grybas conducted the research presented in this study and wrote the paper. Russell G. Congalton contributed to the development of the overall research design, provided guidance along the way, and aided in the writing of the paper.

\section{Conflicts of Interest}

The authors declare no conflict of interest

\section{References}

1. Klemas, V.V. The role of Remote Sensing in predicting and determining coastal storm impacts. J. Coast. Res. 2009, 25, 1264-1275.

2. Bianchette, T.A.; Liu, K.B.; Lam, N.S.; Kiage, L.M. Ecological impacts of hurricane ivan on the gulf coast of Alabama : A remote sensing study. J. Coast. Res. 2009, 2, 1622-1626.

3. Zhang, X.; Wang, Y.; Jiang, H.; Wang, X. Remote-sensing assessment of forest damage by Typhoon Saomai and its related factors at landscape scale. Int. J. Remote Sens. 2013, 34, 7874-7886.

4. Ramsey III, E.W.; Chappell, D.K.; Baldwin, D.G. AVHRR imagery used to identify hurricane damage in a forested wetland of Louisiana. Photogramm. Eng. Remote Sens. 1997, 63, 293-297.

5. Steyer, G.D.; Couvillion, B.R.; Barras, J.A. Monitoring vegetation response to episodic disturbance events by using multitemporal vegetation indices. J. Coast. Res. 2013, doi: http://dx.doi.org/10.2112/SI63-011.1.

6. Rodgers, J.C.; Murrah, A.W.; Cooke, W.H. The impact of hurricane katrina on the coastal vegetation of the weeks bay reserve, alabama from NDVI data. Estuar. Coast. 2009, 32, 496-507.

7. Knutson, T.R.; McBride, J.L.; Chan, J.; Emanuel, K.; Holland, G.; Landsea, C.; Held, I.; Kossin, J.P.; Srivastava, A.K.; Sugi, M. Tropical cyclones and climate change. Nat. Geosci. 2010, 3, 157-163.

8. Webster, P.J.; Holland, G.J.; Curry, J.A.; Chang, H.-R. Changes in tropical cyclone number, duration, and intensity in a warming environment. Science 2005, 309, 1844-1846.

9. Lam, N.S.-N.; Liu, K.-B.; Liang, W.; Bianchette, T.A.; Platt, W.J. Effects of Hurricanes on the Gulf Coast ecosystems: A remote sensing study of land cover change around Weeks Bay, Alabama. J. Coast. Res. 2011, 1707-1711. 
10. Part A: global and sectoral aspects. contribution of working group ii to the fifth assessment report of the intergovernmental panel on climate change. In IPCC Climate Change 2014: Impacts, Adaptation, and Vulnerability; Field, C.B., Barros, V.R., Dokken, D.J., Mach, K.J., Mastrandrea, M.D., Bilir, T.E., Chatterjee, M., Ebi, K.L., Estrada, Y.O., Genova, R.C., et al., Eds.; Cambridge University Press: Cambridge, United Kingdom and New York, NY, USA, 2014; pp. 361-409.

11. Wang, Y.; Christiano, M.; Traber, M. Mapping salt marshes in Jamaica Bay and terrestrial vegetation in Fire Island National Seashore using QuickBird satellite data. In Remote Sensing of Coastal Environments; Weng, Q., Ed.; CRC Press: Boca Raton, FL, USA, 2010; pp. 191-208.

12. Lu, D.; Weng, Q. A survey of image classification methods and techniques for improving classification performance. Int. J. Remote Sens. 2007, 28, 823-870.

13. Ramsey III, E.W.; Jacobs, D.M.; Sapkota, S.K.; Baldwin, D.G. Resource management of forested wetlands: Hurricane impact and recovery mapped by combining Landsat TM and NOAA AVHRR data. Photogramm. Eng. Remote Sens. 1998, 64, 733-738.

14. Ayala-Silva, T.; Twumasi, Y.A. Hurricane Georges and vegetation change in Puerto Rico using AVHRR satellite data. Int. J. Remote Sens. 2004, 25, 1629-1640.

15. Wang, F.; Xu, Y.J. Hurricane Katrina-induced forest damage in relation to ecological factors at landscape scale. Environ. Monit. Assess. 2009, 156, 491-507.

16. Wulder, M.A.; White, J.C.; Goward, S.N.; Masek, J.G.; Irons, J.R.; Herold, M.; Cohen, W.B.; Loveland, T.R.; Woodcock, C.E. Landsat continuity: Issues and opportunities for land cover monitoring. Remote Sens. Environ. 2008, 112, 955-969.

17. Wulder, M.A.; Masek, J.G.; Cohen, W.B.; Loveland, T.R.; Woodcock, C.E. Opening the archive: How free data has enabled the science and monitoring promise of Landsat. Remote Sens. Environ. 2012, 122, 2-10.

18. Roy, D.P.; Wulder, M.A.; Loveland, T.R.; C.E., W.; Allen, R.G.; Anderson, M.C.; Helder, D.; Irons, J.R.; Johnson, D.M.; Kennedy, R.; et al. Landsat-8: Science and product vision for terrestrial global change research. Remote Sens. Environ. 2014, 145, 154-172.

19. USGS Frequently Asked Questions about the Landsat Missions. Availble Online: http://landsat.usgs.gov/ldcm_vs_previous.php (accessed on 30 September 2015).

20. Dube, T.; Mutanga, O. Evaluating the utility of the medium-spatial resolution Landsat 8 multispectral sensor in quantifying aboveground biomass in uMgeni catchment, South Africa. ISPRS J. Photogramm. Remote Sens. 2015, 101, 36-46.

21. Flood, N. Continuity of Reflectance Data between Landsat-7 ETM+ and Landsat-8 OLI, for Both Top-of-Atmosphere and Surface Reflectance: A Study in the Australian Landscape. Remote Sens. 2014, 6, 7952-7970.

22. NASA Landsat 8 Overview. Availble Online: http://landsat.gsfc.nasa.gov/?page_id=7195 (accessed on 30 September 2015).

23. Irons, J.R.; Dwyer, J.L.; Barsi, J.A. The next Landsat satellite: The Landsat data continuity mission. Remote Sens. Environ. 2012, 122, 11-21.

24. Jia, K.; Wei, X.; Gu, X.; Yao, Y.; Xie, X.; Li, B. Land cover classification using Landsat 8 Operational Land Imager data in Beijing, China. Geocarto Int. 2014, 29, 941-951.

25. Poursanidis, D.; Chrysoulakis, N.; Mitraka, Z. Landsat 8 vs. Landsat 5 : A comparison based on urban and peri-urban land cover mapping. Int. J. Appl. Earth Obs. Geoinf. 2015, 35, 259-269. 
26. Ferguson, R.L.; Korfmacher, K. Remote sensing and GIS analysis of seagrass meadows in North Carolina, USA. Aquat. Bot. 1997, 58, 241-258.

27. Vogelmann, J.E.; Sohl, T.; Howard, S.M. Regional characterization of land cover using multiple sources of data. Photogramm. Eng. Remote Sens. 1998, 64, 45-57.

28. Lawrence, R.L.; Wright, A. Rule-based classification systems using classification and regression tree (CART) analysis. Photogramm. Eng. Remote Sensing 2001, 67, 1137-1142.

29. Lathrop, R.G.; Montesano, P.; Haag, S. A multi-scale segmentation approach to mapping seagrass habitats using airborne digital camera imagery. Photogramm. Eng. Remote Sens. 2006, 72, 665-675.

30. Yu, Q.; Gong, P.; Clinton, N.; Biging, G.; Kelly, M.; Schirokauer, D. Object-based detailed vegetation classification with airborne high spatial resolution Remote Sensing imagery. Photogramm. Eng. Remote Sens. 2006, 72, 799-811.

31. Conchedda, G.; Durieux, L.; Mayaux, P. An object-based method for mapping and change analysis in mangrove ecosystems. ISPRS J. Photogramm. Remote Sens. 2008, 63, 578-589.

32. Johansen, K.; Arroyo, L.A.; Phinn, S.; Witte, C. Comparison of geo-object based and pixel-based change detection of riparian environments using high spatial resolution multi-spectral imagery. Photogramm. Eng. Remote Sens. 2010, 76, 123-136.

33. Blaschke, T. Object based image analysis for remote sensing. ISPRS J. Photogramm. Remote Sens. 2010, 65, 2-16.

34. Blaschke, T.; Hay, G.J.; Kelly, M.; Lang, S.; Hofmann, P.; Addink, E.; Queiroz Feitosa, R.; van der Meer, F.; van der Werff, H.; van Coillie, F.; et al. Geographic object-based image analysis - Towards a new paradigm. ISPRS J. Photogramm. Remote Sens. 2014, 87, 180-191.

35. Whiteside, T.G.; Boggs, G.S.; Maier, S.W. Comparing object-based and pixel-based classifications for mapping savannas. Int. J. Appl. Earth Obs. Geoinf. 2011, 13, 884-893.

36. Flanders, D.; Hall-Beyer, M.; Pereverzoff, J. Preliminary evaluation of eCognition object-based software for cut block delineation and feature extraction. Can. J. Remote Sens. 2003, 29, 441-452.

37. Yan, G.; Mas, J.-F.; Maathuis, B.H.P.; Xiangmin, Z.; Van Dijk, P.M. Comparison of pixel-based and object-oriented image classification approaches - A case study in a coal fire area, Wuda, Inner Mongolia, China. Int. J. Remote Sens. 2006, 27, 4039-4055.

38. Campbell, M.; Congalton, R.G.; Hartter, J.; Ducey, M. Optimal land cover mapping and change analysis in northeastern oregon using Landsat imagery. Photogramm. Eng. Remote Sens. 2015, 81, $37-47$.

39. Robertson, L.D.; King, D.J. Comparison of pixel- and object-based classification in land cover change mapping. Int. J. Remote Sens. 2011, 32, 1505-1529.

40. Duro, D.C.; Franklin, S.E.; Dubé, M.G. A comparison of pixel-based and object-based image analysis with selected machine learning algorithms for the classification of agricultural landscapes using SPOT-5 HRG imagery. Remote Sens. Environ. 2012, 118, 259-272.

41. Hussain, M.; Chen, D.; Cheng, A.; Wei, H.; Stanley, D. Change detection from remotely sensed images: From pixel-based to object-based approaches. ISPRS J. Photogramm. Remote Sens. 2013, 80, 91-106.

42. Coppin, P.; Jonckheere, I.; Nackaerts, K.; Muys, B.; Lambin, E. Review ArticleDigital change detection methods in ecosystem monitoring: A review. Int. J. Remote Sens. 2004, 25, 1565-1596. 
43. Dobson, J.E.; Bright, E.A.; Ferguson, R.L.; Field, D.W.; Wood, L.; Haddad, K.D.; Iredale III, H.; Jensen, J.R.; Klemas, V.V.; Orth, J.R.; et al. NOAA Coastal Change Analysis Program (C-CAP): Guidance for Regional Implementation. NOAA Technical Report NMFS 123: Seattle, WA, USA, 1995.

44. Schupp, C. Assateague Island National Seashore Geologic Resources Inventory Report; Natural resource report NPS/NRSS/GRD/NRR_2013/708: Fort Collins, CO, USA, 2013.

45. Carruthers, T.; Beckert, K.; Dennison, B.; Thomas, J.; Saxby, T.; Williams, M.; Fisher, T.; Kumer, J.; Schupp, C.; Sturgis, B.; et al. Assateague Island National Seashore Natural Resource Condition Assessment Maryland Virginia; Natural Resource Report NPS/ASIS/NRR-2011/405: Fort Collins, CO, USA, 2011.

46. Carruthers, T.; Beckert, K.; Schupp, C.A.; Saxby, T.; Kumer, J.P.; Thomas, J.; Sturgis, B.; Dennison, W.C.; Williams, M.; Fisher, T.; et al. Improving management of a mid-Atlantic coastal barrier island through assessment of habitat condition. Estuar. Coast. Shelf Sci. 2013, 116, 74-86.

47. Krantz, D.E.; Schupp, C.; Spaur, C.C.; Thomas, J. .; Wells, D. . Dynamic systems at the land-sea interface. In Shifting Sands: Environmental and Cultural Change in Maryland's Coastal Bays; Dennison, W.C., Thomas, J., Cain, C.J., Carruthers, T., Hall, M.R., Jesien, R.V., Wazniak, C.E., Wilson, D.E., Eds.; IAN Press: Cambridge, MD, USA, 2009; pp. 193-230.

48. Intergraph. ERDAS Field Guide; Intergraph Corporation: Huntsville, AL, USA, 2013.

49. Chavez, P.S. Image-based atmospheric corrections-Revisited and improved. Photogramm. Eng. Remote Sens. 1996, 62, 1025-1036.

50. Chander, G.; Markham, B.L.; Helder, D.L. Summary of current radiometric calibration coefficients for Landsat MSS, TM, ETM+, and EO-1 ALI sensors. Remote Sens. Environ. 2009, 113, 893-903.

51. Crist, E.P.; Laurin, R.; Cicone, R. Vegetation and soils information contained in transformed Thematic Mapper data. In Proceedings of IGARSS' 86 Symposium: Zurich, Switzerland, 8-11 September 1986; pp. 1465-1470.

52. Baig, M.H.A.; Zhang, L.; Shuai, T.; Tong, Q. Derivation of a tasselled cap transformation based on Landsat 8 at-satellite reflectance. Remote Sens. Lett. 2014, 5, 423-431.

53. Congalton, R.G.; Green, K. Assessing the Accuracy of Remotely Sensed Data: Principles and Practices, 2nd ed.; CRC Press: Boca Raton, FL, USA, 2009.

54. Congalton, R.G. Using spatial autocorrelation analysis to explore the errors in maps generated from remotely sensed data. Photogramm. Eng. Remote Sens. 1988, 54, 587-592.

55. Trimble. eCognition Developer 9.0 User Guide; TrimbleGermany GmbH: Munich, Germany, 2014.

56. Kim, M.; Warner, T.A.; Madden, M.; Atkinson, D.S. Multi-scale GEOBIA with very high spatial resolution digital aerial imagery: Scale, texture and image objects. Int. J. Remote Sens. 2011, 32, 2825-2850.

57. Kim, M.; Madden, M.; Warner, T. Estimation of optimal image object size for the segmentation of forest stands with multispectral IKONOS imagery. In Object-Based Image Analysis-Spatial Concepts for Knowledge-Driven Remote Sensing Applications; Blaschke, T., Lang, S., Hay, G.J., Eds.; Springer-Verlag: Berlin, Heidelberg, 2008; pp. 291-307.

58. Drăguţ, L.; Tiede, D.; Levick, S.R. ESP: A tool to estimate scale parameter for multiresolution image segmentation of remotely sensed data. Int. J. Geogr. Inf. Sci. 2010, 24, 859-871. 
59. Drăguţ, L.; Csillik, O.; Eisank, C.; Tiede, D. Automated parameterisation for multi-scale image segmentation on multiple layers. ISPRS J. Photogramm. Remote Sens. 2014, 88, 119-127.

60. Espindola, G.M.; Camara, G.; Reis, I.A.; Bins, L.S.; Monteiro, A.M. Parameter selection for region-growing image segmentation algorithms using spatial autocorrelation. Int. J. Remote Sens. 2006, 27, 3035-3040.

61. Breiman, L. Random forests. Mach. Learn. 2001, 45, 5-32.

62. Rodriguez-Galiano, V.F.; Ghimire, B.; Rogan, J.; Chica-Olmo, M.; Rigol-Sanchez, J.P. An assessment of the effectiveness of a random forest classifier for land-cover classification. ISPRS J. Photogramm. Remote Sens. 2012, 67, 93-104.

63. Congalton, R.G.; Oderwald, R.G.; Mead, R.A. Assessing Landsat classification accuracy using discrete multivariate analysis statistical techniques. Photogramm. Eng. Remote Sens. 1983, 49, 1671-1678.

64. MacLean, M.G.; Congalton, R.G. Map accuracy assessment issues when using an object-oriented approach. In Proceedings of American Society of Photogrammetry \& Remote Sensing 2012 Annual Conference, Sacramento, CA, USA, 19-23 March 2012; p. 5.

65. Xian, G.; Homer, C.; Fry, J. Updating the 2001 national land cover database land cover classification to 2006 by using Landsat imagery change detection methods. Remote Sens. Environ. 2009, 113, 1133-1147.

66. Story, M.; Congalton, R.G. Accuracy assessment : A user's perspective. Photogramm. Eng. Remote Sens. 1986, 52, 397-399.

67. Liu, Q.; Liu, G.; Huang, C.; Xie, C. Comparison of tasselled cap transformations based on the selective bands of Landsat 8 OLI TOA reflectance images. Int. J. Remote Sens. 2015, 36, 417-441.

68. Baker, B.A.; Warner, T.A.; Conley, J.F.; McNeil, B.E. Does spatial resolution matter? A multi-scale comparison of object-based and pixel-based methods for detecting change associated with gas well drilling operations. Int. J. Remote Sens. 2013, 34, 1633-1651.

69. Chen, G.; Hay, G.J.; Carvalho, L.M.T.; Wulder, M.A. Object-based change detection. Int. J. Remote Sens. 2012, 33, 4434-4457.

70. McDermid, G.J.; Linke, J.; Pape, A.D.; Laskin, D.N.; McLane, A.J.; Franklin, S.E. Object-based approaches to change analysis and thematic map update: Challenges and limitations. Can. J. Remote Sens. 2008, 34, 462-466.

(C) 2015 by the authors; licensee MDPI, Basel, Switzerland. This article is an open access article distributed under the terms and conditions of the Creative Commons Attribution license (http://creativecommons.org/licenses/by/4.0/). 